\title{
A 1.1-1.9 GHz SETI SURVEY OF THE KEPLER FIELD. I. A SEARCH FOR NARROW-BAND EMISSION FROM SELECT TARGETS
}

\author{
Andrew P. V. Siemion ${ }^{1}$, Paul Demorest $^{2}$, Eric Korpela ${ }^{1}$, Ron J. Maddalena ${ }^{2}$, Dan Werthimer ${ }^{1}$, Jeff Cobi $^{1}$, \\ Andrew W. Howard ${ }^{3}$, Glen Langston ${ }^{2}$, Matt Lebofsky ${ }^{1}$, Geoffrey W. Marcy ${ }^{1}$, and Jill Tarter ${ }^{4}$ \\ ${ }^{1}$ University of California, Berkeley, 110 Sproul Hall, Berkeley, CA 94720, USA \\ ${ }^{2}$ National Radio Astronomy Observatory, 520 Edgemont Rd Charlottesville, VA 22903, USA \\ ${ }^{3}$ Institute for Astronomy, University of Hawaii, 640 North A'ohōkū Place, \#209 Hilo, HI 96720-2700, USA \\ ${ }^{4}$ SETI Institute, 189 Bernardo Ave \#100 Mountain View, CA 94043, USA \\ Received 2012 December 6; accepted 2013 February 3; published 2013 March 28
}

\begin{abstract}
We present a targeted search for narrow-band $(<5 \mathrm{~Hz})$ drifting sinusoidal radio emission from 86 stars in the Kepler field hosting confirmed or candidate exoplanets. Radio emission less than $5 \mathrm{~Hz}$ in spectral extent is currently known to only arise from artificial sources. The stars searched were chosen based on the properties of their putative exoplanets, including stars hosting candidates with $380 \mathrm{~K}>T_{\mathrm{eq}}>230 \mathrm{~K}$, stars with five or more detected candidates or stars with a super-Earth $\left(R_{\mathrm{p}}<3 R_{\oplus}\right)$ in a $>50$ day orbit. Baseband voltage data across the entire band between 1.1 and 1.9 GHz were recorded at the Robert C. Byrd Green Bank Telescope between 2011 February and April and subsequently searched offline. No signals of extraterrestrial origin were found. We estimate that fewer than $\sim 1 \%$ of transiting exoplanet systems host technological civilizations that are radio loud in narrow-band emission between 1 and $2 \mathrm{GHz}$ at an equivalent isotropically radiated power (EIRP) of $\sim 1.5 \times 10^{21} \mathrm{erg} \mathrm{s}^{-1}$, approximately eight times the peak EIRP of the Arecibo Planetary Radar, and we limit the number of $1-2 \mathrm{GHz}$ narrow-band-radio-loud Kardashev type II civilizations in the Milky Way to be $<10^{-6} M_{\odot}^{-1}$. Here we describe our observations, data reduction procedures and results.
\end{abstract}

Key words: astrobiology - extraterrestrial intelligence - planets and satellites: detection - planets and satellites: general - surveys

Online-only material: color figures

\section{INTRODUCTION}

In the last 50 years, evidence has steadily mounted that the constituents and conditions we believe necessary for life are common and perhaps ubiquitous in the nearby galaxy. A plethora of prebiotic molecules have now been detected in molecular clouds, including amino acids and their precursors (Mehringer et al. 1997; Kuan et al. 2003), sugars (Hollis et al. 2004) and a host of other biologically important species (e.g., Lovas et al. 2006; Iglesias-Groth 2011). Such detections offer an indication that the reactants necessary for building large complex organic structures may be formed readily in proto-planetary environs. Exoplanets themselves, while once relegated to the domain of speculation, now appear to be common and numerous. While strictly Earth-size exoplanets at 1 AU from their Solar-type parents have so far eluded detection, we have evidence that the conditions necessary to maintain carbon-based life, e.g., liquid water, can exist far away from the traditional "habitable zone" (Carr et al. 1998).

As yet, no evidence exists for the presence of any kind of life outside of the Earth. However, on our own planet, life is known to have arisen early (within $1 \mathrm{Gyr}$ ) and flourished (Schopf et al. 2002). And while the propensity for evolution of intelligence from basic forms of life is not currently well understood, it appears that intelligence has imparted a strong evolutionary advantage to our own species. From a Copernican standpoint, the possibility that life has arisen elsewhere and perhaps evolved intelligence is plausible and warrants scientific inquiry. "Are we alone as technologically-capable intelligent beings?" is among the most profound questions we can ask as scientists, and observational astronomy represents the best means of determining an answer.

\subsection{Engineered Radio Emission}

For a better part of the last century, human beings have produced radio emissions that could readily be recognized as having come from no known natural source if transmitted at sufficient power from another star and received on Earth. These emissions include spectrally narrow signals, e.g., the sinusoidal carrier waves associated with frequency modulated or amplitude modulated telecommunications, as well as temporally narrow radio pulses used for radar. Long wavelength radio photons are efficient and effective interstellar information carriers, as they are energetically cheap and the interstellar medium (ISM) is relatively transparent at radio wavelengths. The frequency band between $\sim 500 \mathrm{MHz}$ and $10 \mathrm{GHz}$, the so-called "terrestrial microwave window" (Morrison et al. 1977) is especially attractive for terrestrial transmission or reception, in that it represents a relatively quiet region of spectrum between the Galactic synchrotron-dominated low frequency spectrum and atmospheric $\mathrm{H}_{2} \mathrm{O}$ and $\mathrm{O}_{2}$ emission and absorption.

Natural astrophysical electromagnetic emissions are inherently spectrally broadened by the random processes underlying natural emission physics, with the spectrally narrowest known natural sources, astrophysical masers, having a minimum frequency spread of $\sim 500 \mathrm{~Hz}$ (Cohen et al. 1987). Emission no more than a few $\mathrm{Hz}$ in spectral width is, as far as we know, an unmistakable indicator of engineering by an intelligent civilization. While scintillation effects can render an intrinsically amplitude-stable narrow-band signal intermittent (Cordes et al. 1997), narrow-band signals are readily distinguished from background sources of radio emission and are immune to the dispersive effects of the interstellar medium. Broadband pulsed radio emissions are more deleteriously affected by the ISM, as 
evidenced by decades of pulsar research, but they too are easily distinguished from incoherent emission and the few thousand known pulsars do not represent a significant interfering background. Further, some have suggested that directing large amounts of energy into broadband pulsed emission might be attractive than a narrow band transmitter for an economical advanced civilization (Benford et al. 2008).

Although the technologies associated with engineered radio emissions from Earth are developed by humans, similar signal types may be used by extraterrestrial intelligent civilizations if they similarly use electromagnetic radiation for ranging and communication. It is difficult to predict the specific properties of electromagnetic emission from extraterrestrial technologies, but if an extraterrestrial civilization is intentionally indicating its presence via such emission, it would be beneficial to make the signal discriminable. In terms of distinguishability, both pulsed signals and narrow band signals possess merit, and it is prudent to search for both. Extrapolating from humanity's exploration of space, it is likely that a more advanced civilization having similar proclivities would explore and perhaps colonize multiple planets in their star system. These explorations could very easily include planet-planet communication and radar imaging or radar mapping of orbital debris. Observing planetary systems in which the orbital plane is seen edge-on, such as those identified by transiting exoplanet surveys, thus present a particularly advantageous geometry for eavesdropping on planet-planet electromagnetic signaling by advanced life.

\section{OBSERVATIONS}

SETI observations were performed during the period 2011 February-April using the Robert C. Byrd Green Bank Telescope (GBT) $L$-band (1.1-1.9 GHz) receiver and the Green Bank Ultimate Pulsar Processor (GUPPI) digital backend (P. Demorest et al. 2013, in preparation). For this experiment, GUPPI was configured in a novel "baseband recording" mode in which an entire $800 \mathrm{MHz}$ band is digitized, channelized to 3.125 MHz with a 256-point polyphase filterbank and written to disk as 2-bit voltage data for both $X$ and $Y$ linear polarizations. The total aggregate data rate in this mode is $800 \mathrm{MBps}$. In order to obtain the requisite disk recording rates, the data stream was distributed to GUPPI's eight CPU/GPU computing nodes at 32 channels/node and eight $100 \mathrm{MHz}$ bands were recorded separately. For the purposes of analysis, we have considered each $100 \mathrm{MHz}$ band individually, hereafter Bands 0-7. We use this convention primarily because early technical problems with the GUPPI backend resulted in some computing nodes failing to record data, thus causing some observations to have noncontiguous frequency coverage in $100 \mathrm{MHz}$ increments (see Table 3).

Targeted observations were performed on 86 Kepler Objects of Interest (KOIs) hosting planet candidates judged to be most amenable to the presence of Earth-like life, primarily judged by equilibrium temperature, but also cursory similarity to the Earth and the Solar system. These targets comprised KOIs hosting planet candidates in or near the traditional "habitable zone" (380 K $\left.>T_{\text {eq }}>230 \mathrm{~K}\right)$ as described in Kasting et al. (1993), all KOIs hosting five or more planet candidates and all KOIs hosting a super-Earth $\left(R_{\mathrm{p}}<3 R_{\oplus}\right)$ in a $>50$ day orbit. Equilibrium temperatures were taken from Borucki et al. (2011), and the extended habitable zone range included in our search reflects their quoted uncertainty of approximately 22\%. Temperatures were calculated assuming a Bond albedo, emissivity of 0.9 , and a uniform surface temperature (see Borucki et al. 2011). An
Table 1

Targeted Observation Parameters

\begin{tabular}{lcc}
\hline \hline Center Frequency & $v_{o}$ & $1500 \mathrm{MHz}$ \\
Bandwidth & $\Delta v$ & $800 \mathrm{MHz}^{\mathrm{a}}$ \\
Beam Width & $\Theta$ & $9^{\prime}$ \\
(HPBW) & & \\
System Temperature & & \\
Gain $^{\mathrm{b}}$ & $T_{\text {sys }}$ & $20 \mathrm{~K}$ \\
SEFD $^{\mathrm{b}}$ & $G$ & $2.0 \mathrm{~K} \mathrm{Jy}^{-1}$ \\
Observation Time per Source $^{\mathrm{b}}$ & $S_{\text {sys }}$ & $10 \mathrm{Jy}$ \\
& $t_{\mathrm{obs}}$ & $300 \mathrm{~s}$ \\
\hline
\end{tabular}

Notes.

a Excluding the band 1.2-1.33 GHz, see main text.

b Nominal value.

additional 19 KOIs located within a half power beam width of a primary target were observed serendipitously. Observations were performed using a cadence in which each target was observed interleaved with another target separated by $\Theta_{\min }>1^{\circ}$ such that each target was effectively observed with an onsource, off-source, on-source sequence with minimal overhead. This technique is crucial for discerning a true astronomical signal from ubiquitous interference from human technologies. Details of the parameters of our observations are presented in Table 1. The observations discussed here represent part of a larger $24 \mathrm{hr}$ campaign to search for technologically produced radio emissions in the Kepler field, which included both targeted observations and a raster scan of the entire field. Additional work, in preparation, will discuss a narrow-band search of the raster scan data and pulse searches over both targeted and raster observations.

\section{DATA REDUCTION}

To maximize the signal-to-noise of the detection of a distant continuous-wave transmitter the relative motion between the transmitter and receiver must be accounted for. As we have no a priori knowledge of the specific frequency of emission from an extraterrestrial technology, the overall Doppler shift in the received signal, dominated by the radial velocity of the source, is relatively unimportant for detection. However, the time rate of change of the Doppler shift, dominated by the orbital and rotational motions of the transmitter and receiver, must be considered to integrate $\sim \mathrm{Hz}$ spectra over many seconds. The Doppler drift is given simply by

$$
\dot{f}=\frac{d \vec{V}}{d t} \frac{f_{\text {rest }}}{c}
$$

where $\vec{V}$ is the line of sight relative velocity between receiver and source, $f_{\text {rest }}$ is the rest frequency of the transmitter, and $c$ the speed of light. As a point of reference, the maximum contribution from Earth's orbital motion at $1 \mathrm{GHz}$ is $\sim \pm 0.02 \mathrm{~Hz} \mathrm{~s}^{-1}$, and from Earth's rotation is $\sim-0.1 \mathrm{~Hz} \mathrm{~s}^{-1}$. If this effect is corrected for in power spectra, the worst-case minimum achievable spectral resolution for terrestrial observations is thus about $\Delta v=0.3$ $\mathrm{Hz}$ (at $1 \mathrm{GHz}$ ). Channelization to any finer resolution would be ineffective as the received signal would be smeared over several channels. While the Doppler drift due to Earth's motion is known, the drift due to possible motion of the transmitter is largely unknown. For observations where $t_{\mathrm{obs}} \delta f>\Delta v$, this necessitates searching various Doppler drift rates to achieve a $\sqrt{t_{\mathrm{obs}}}$ increase in sensitivity. As an aside, an arbitrary Doppler drift can be removed exactly in the voltage domain with no loss 


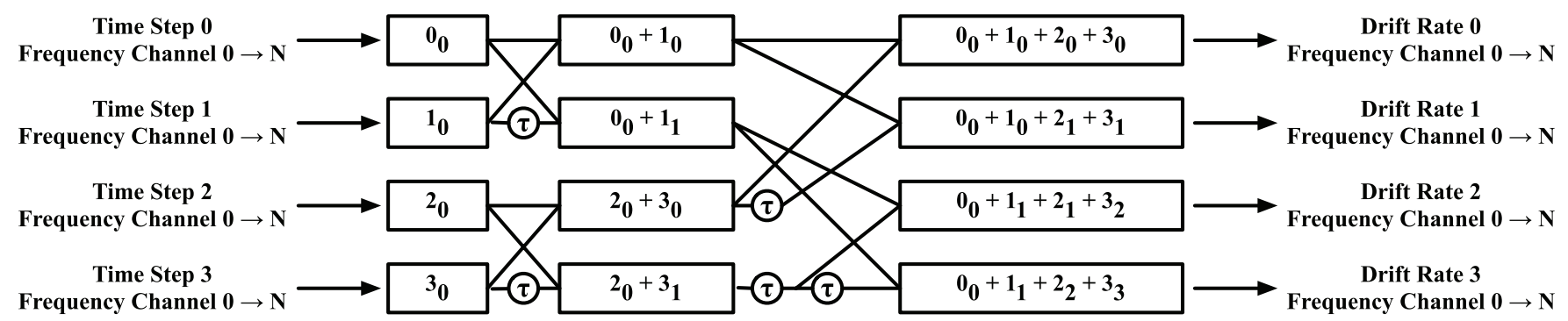

Figure 1. A diagram of the "tree deDoppler" algorithm used to search for sinusoids drifting due to Doppler acceleration, shown here for four power spectra each having $N$ frequency channels.

in sensitivity, via multiplication by an appropriate chirp function (Leigh 1998), but this technique is computationally infeasible for most blind searches, an exception being SETI@ home (Korpela et al. 2002).

We accomplished a search for narrow-band features drifting at rates up to $\sim \pm 10 \mathrm{~Hz} \mathrm{~s}^{-1}$ using a modified form of the "tree" dedispersion algorithm, an algorithm originally developed for searching for dispersed pulsar emission (Taylor 1974). In much the same way that dispersed pulse searches seek to find power distributed along a quadratic curve in the time-frequency plane, a search for drifting sinusoids seeks to find approximately linearly drifting features in the same plane. The difference is simply one of the dimensions and orientation of the time-frequency matrix. The tree dedispersion algorithm accelerates these searches by taking advantage of the redundant computations involved in searching similar slopes, reducing the number of additions required from $n^{2}$ to $n \log _{2} n$, where $n$ is equal to both the number of spectra and number of slopes searched. Figure 1 shows a diagram of the "tree deDoppler" algorithm implemented for the drifting sinusoid search, shown here for four power spectra each having $N$ frequency channels. The tree algorithm has fallen into disuse in the pulsar community due to the fact that it intrinsically sums only linear slopes, and modern broadband pulsar observations require a more exact quadratic sum to follow the $v^{-2}$ cold plasma dispersion relation. In the case of Doppler drifting sinusoids, the linear approximation is very good and the tree algorithm is an excellent fit to the problem.

Our implementation of the "tree deDoppler" algorithm necessitates $2^{m}$ spectra (an integer power of 2) and searches $2^{m}$ Doppler drift rates out to a maximum drift rate of:

$$
\dot{f}_{\max }=(\Delta v)^{2}
$$

where $\Delta v$ is the spectral resolution. The drift rate resolution is constrained to:

$$
\Delta \dot{f}=\frac{\Delta v}{T_{\mathrm{obs}}}
$$

where $T_{\text {obs }}$ is the total observing time. We performed three channelizations at resolutions ranging from $0.75 \mathrm{~Hz}$ to $2.98 \mathrm{~Hz}$, giving the maximum drift rates and drift resolutions shown in Table 2. The maximum drift rate searched would accommodate an equatorial transmitter on a planet 5 times larger and rotating 5 times faster than Earth.

Prior to Doppler searching, each $3.125 \mathrm{MHz}$ polyphase channel was further channelized to $\sim \mathrm{Hz}$ resolution, detected and thresholded to search for narrow-band features. After detection, both polarizations were summed to form a single spectrum. Each high resolution spectrum constructed from individual polyphase channels was corrected for the filter response imposed by first stage (GUPPI) channelization by dividing through with
Table 2

Narrowband Search Parameters

\begin{tabular}{lcc}
\hline \hline $\begin{array}{l}\text { Spectral Resolution } \\
(\mathrm{Hz})\end{array}$ & $\begin{array}{c}\text { Drift Resolution } \\
\left(\mathrm{Hz} \mathrm{s}^{-1}\right)\end{array}$ & $\begin{array}{c}\text { Maximum Drift Rate } \\
\left(\mathrm{Hz} \mathrm{s}^{-1}\right)\end{array}$ \\
\hline 2.98 & 0.020 & 8.88 \\
1.49 & 0.010 & 2.22 \\
0.75 & 0.005 & 0.56 \\
\hline
\end{tabular}

Note. ${ }^{\text {a }}$ Characteristic value, exact resolution depends on the specific duration of each observation.

a polynomial fit to an average bandpass. This polynomial fit bandpass was constructed a priori by fitting to a sum of many coarsely channelized spectra exhibiting low interference (based on visual inspection). All $M$ spectra having length $N$ from a single observation were then fit into a matrix sized to the nearest larger matrix having dimensions $2^{m} \times N$. Because we can assume that an untargeted narrow-band signal transmitted by an extraterrestrial technology will either be drifting due to acceleration in the host system or transmitted uncorrected for the Doppler acceleration at the receiving observatory, any narrowband signal exhibiting no drift can be ruled out as likely coming from a terrestrial source. This concept is analogous to searches for pulsars in which sources exhibiting no dispersive sweep in their pulse profiles are likely pulsed terrestrial interference. The analogy allows us to again borrow from pulsar search techniques and apply a median filter for sources exhibiting no drift (see, e.g., Eatough et al. 2009; Siemion et al. 2012). After dividing each spectral channel by its median value, the tree deDoppler algorithm was applied in-place. Each Doppler corrected spectrum was then collapsed in time and searched for any summed spectral channel exceeding 25 standard deviations above the mean, assuming Gaussian statistics, with results inserted into a database. We use the term "detection" to refer to one measurement of a unique signal or emitter. Depending on source intensity, a single signal or emitter can be detected multiple times at different drift rates and bandwidths. The set of all detections for frequencies $\nu$, standard deviations $\sigma$, drift rates $\dot{f}$, and bandwidths $\Delta v$ was searched to identify the detection having the largest $\sigma$ within each spectral window of width $\dot{f}_{\text {max }} T_{\text {obs }}$, and a time-frequency waterfall plot around this detection was extracted and stored with the corresponding database entry. We hereafter characterize each of the highest $\sigma$ detections as "candidate signals." Ultimately we were left with approximately $3 \times 10^{5}$ candidate signals.

Although the ISM is relatively unobtrusive to narrow-band radio emission, relative to, e.g., interstellar dust on optical light, and the atmosphere (including the ionosphere) is essentially transparent between 1 and $10 \mathrm{GHz}$, the signals being considered here are not wholly unperturbed by the intervening media. 
The ISM has been considered in the context of SETI for some time, notably in Cordes \& Lazio (1991), Cordes et al. (1997) and references therein, with the principal results being as follows. In the strong scattering regime, narrow band sinusoids experience limited spectral broadening due to scattering in the inhomogeneous interstellar plasma, with a bandwidth $\Delta v_{\text {broad }}$ equal to:

$$
\Delta v_{\text {broad }}=0.097 \mathrm{~Hz} v_{\mathrm{GHz}}^{-6 / 5}\left(\frac{V_{\perp}}{100}\right) \mathrm{SM}^{3 / 5}
$$

Where $V_{\perp}$ is the transverse velocity of the source in $\mathrm{km} \mathrm{s}^{-1}$ and SM the scattering measure, a measure of the electron density fluctuations $C_{n_{e}}^{2}$, (cf. Rickett 1990) integrated along the line of sight:

$$
\mathrm{SM}=\int_{0}^{L} C_{n_{e}}^{2}(z) d z
$$

Further, intrinsically amplitude-stable narrow-band emission can be modulated in intensity up to $100 \%$ by strong scattering in the inhomogeneous plasma, with a characteristic time scale $\Delta t_{d}$ equal to:

$$
\Delta t_{d}=3.3 \mathrm{~s} v_{\mathrm{GHz}}^{6 / 5}\left(\frac{V_{\perp}}{100}\right)^{-1} \mathrm{SM}^{-3 / 5}
$$

Taking values of the SM from the "NE2001" electron density model (Cordes \& Lazio 2002) for a center-field Kepler star at $0.5 \mathrm{kpc}$ and assuming a transverse velocity of $25 \mathrm{~km} \mathrm{~s}^{-1}$, we calculate $\Delta t_{d} \approx 3.5 \mathrm{hr}$ and $\Delta v_{\text {broad }} \approx 20 \mu \mathrm{Hz}$.

We note that the transition from strong to weak ISM scattering for our observing band occurs at a distance of about 900 ly in the direction of the Kepler field, putting many of our targets in the transition or weak scattering regimes. Although the expressions for $\Delta v$ and $\Delta t_{d}$ differ for these cases (see, e.g., Rickett 1990), the predicted broadening is similarly negligible, intensity modulations significantly lower in amplitude and modulation time scale longer in duration.

Depending on line of sight, the solar wind and interplanetary medium (IPM) can also impose significant spectral broadening on a transiting narrow-band signal. Radio scintillation due to the IPM had been known for some time prior to the discovery of strong scattering in the ISM, studied primarily through angular broadening of distant compact radio sources (see Narayan 1992 and references therein). The presence of spacecraft that could be used as monochromatic and coherent radio test sources allowed an additional probe of the IPM, notably providing a means to measure not just electron density fluctuations but also solar wind velocity (Woo 1978; Woo \& Armstrong 1979), through observations of spectral broadening and phase scintillation of their narrow carrier signals. The strength of these effects depend largely on the solar impact distance $R$, or line-of-sight solar separation angle, but significant longitudinal and temporal (e.g., the solar cycle and coronal mass ejections) variations occur as well (Morabito 2009). Woo (2007) presents an assimilation of phase scintillation and spectral broadening observations of the $S$-band $(2.3 \mathrm{GHz})$ carrier on Pioneer and Helios spacecraft at solar impact distances up to $200 R_{\odot}$ (adapted from Woo 1978), and find a roughly $R^{-9 / 5}$ dependence for spectral broadening past $R \sim 10 R_{\odot}$. A variety of models and observations suggest that the electron density fluctuations in the solar wind follow an approximate power law density spectrum, with a mean index very close to the Kolmogorov value of 5/3 (Morabito 2009 and references therein), allowing these results to be extrapolated based on $\Delta v_{\text {broad }}$ scaling as $v^{-6 / 5}$. Scaling based on the results in Woo (2007), we calculate a spectral broadening contribution from the IPM of approximately:

$$
\Delta \nu_{\text {broad }}=300 \mathrm{~Hz} v_{\mathrm{GHz}}^{-6 / 5}\left(\frac{R}{R_{\odot}}\right)^{-9 / 5}
$$

for solar impact distances greater than $\sim 10 R_{\odot}$.

For our observations, the nearest solar impact distance was $\sim 195 R_{\odot}$, giving an IPM spectral broadening contribution of $\sim 14 \mathrm{mHz}$.

For the parameters of this search, we can thus neglect spectral broadening due to either the ISM or IPM, and can assume a relatively steady flux for any intrinsically continuous and amplitudestable signal over the course of our observing cadence. A key result of Cordes \& Lazio (1991) was the suggestion that searches for narrow-band emissions in the strong scattering regime would have an increased likelihood of detecting a source by observing a sky location multiple times spanning many $\Delta t_{d}$. Although this is a very well justified strategy, the extra observing overhead associated with performing multiple on-off-on observation sequences did not permit it to be used here.

\section{ANALYSIS}

The principal complication in the otherwise straightforward data reduction involved in a narrow-band SETI experiment is the fact that human radio technology produces copious narrow band emission at $\sim \mathrm{Hz}$ scales. The existence of radio frequency interference is not unique to SETI experiments, of course, and over the years many techniques have been developed to mitigate its effects. It is worth noting, however, that in radio observations of most astrophysical phenomena, narrow-band features in a power spectrum can be immediately flagged and discarded because they are known to originate with technology rather than the target of the observation. Narrow-band radio SETI experiments face the more difficult task of determining whether a narrow-band feature originates with a human technology or distant intelligent life.

Our strategy to mitigate terrestrial interference was to demand that a candidate signal be both persistent and isolated on the celestial sphere. By observing in an on-off-on source cadence, we imposed this constraint by requiring that a given candidate signal be detected in both "on" source observations and not in the intervening "off" source observation. Observations in which one of the elements of the on-off-on cadence was not obtained due to technical problems were excluded completely. This technique was very effective, ruling out $99.96 \%$ of the candidate signals. Figure 2 shows a histogram of the number of detections versus signal-to-noise ratio for all detections, the detections representing the most significant detection of a single emitter (candidate signals) and only those detections passing the on-off-on automated interference excision algorithm. Figure 3 shows the number of detected signals as a function of topocentric frequency for the same detection groups. Time-frequency waterfall plots of the remaining 52 candidate signals were examined visually. Of these, 37 were ruled out immediately because candidates detected during pointings at many targets exhibited very similar modulation at nearby frequencies $( \pm 1 \mathrm{MHz})$. The remaining 15 signals were ruled out after querying the entire database of candidate signals for detections within $\pm 1 \mathrm{MHz}$ and identifying signals detected during pointings at other targets that closely resembled the modulation and drift properties of the candidate signals. Figure 4 shows two candidate signals 


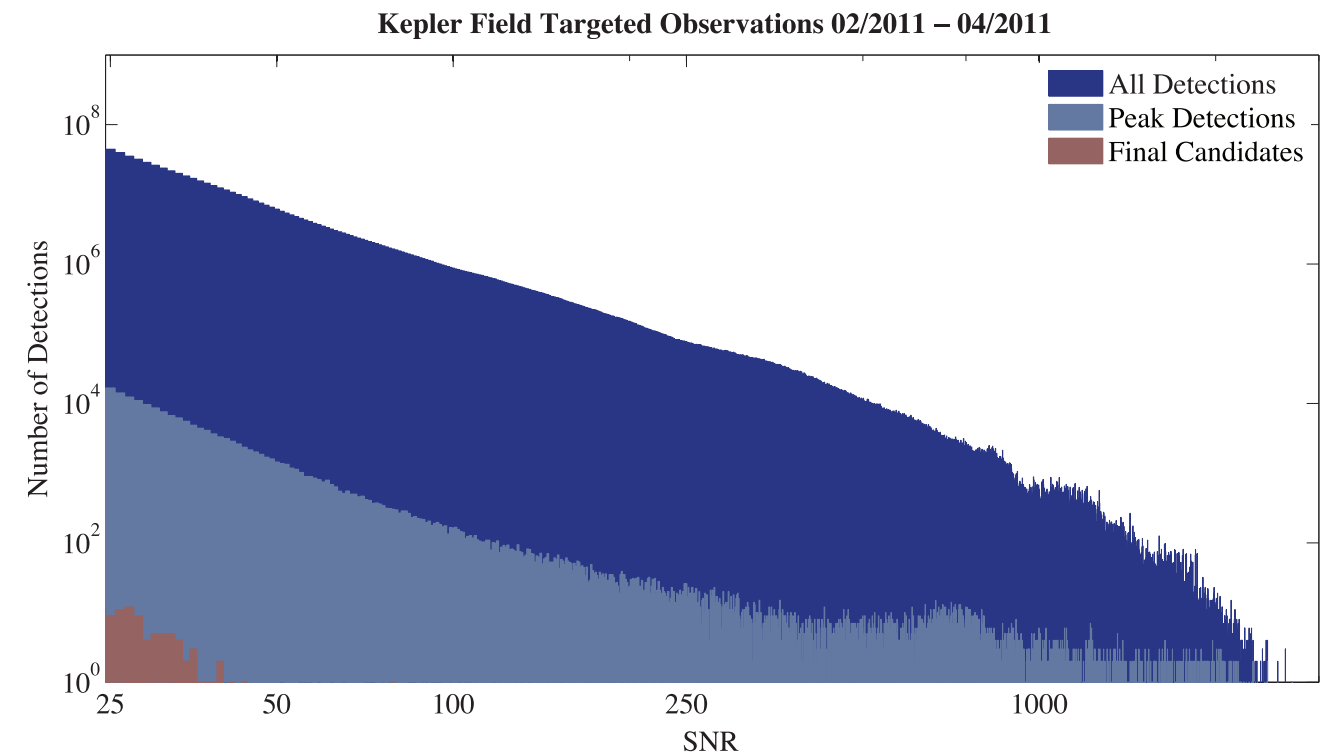

Figure 2. Number of detections vs. signal-to-noise ratio for the set of all detections, the detections representing the most significant detection of a single signal and only those candidates passing an automated interference excision algorithm (see Section 4).

(A color version of this figure is available in the online journal.)

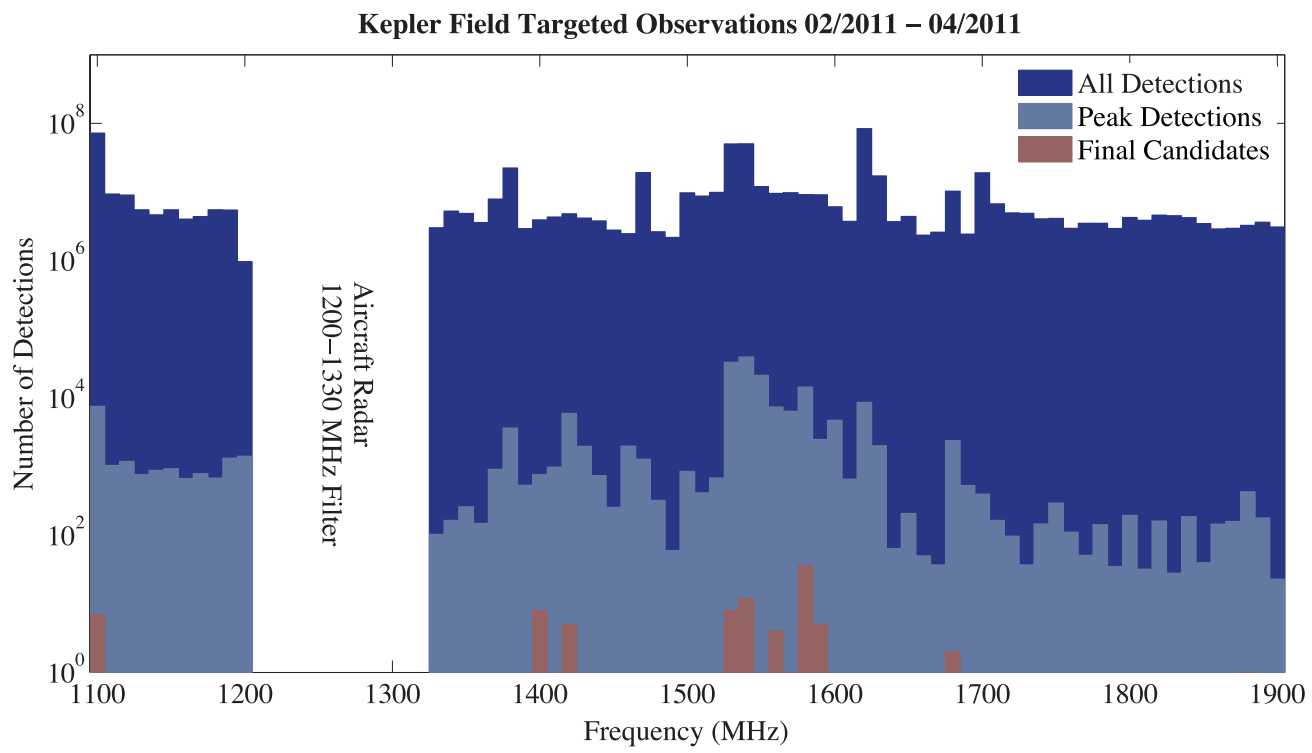

Figure 3. Number of detections vs. topocentric frequency for the set of all detections, the detections representing the most significant detection of a single signal and only those candidates passing an automated interference excision algorithm (see Section 4). A region of spectrum between 1200 and $1330 \mathrm{MHz}$ was excluded due to the presence of a strong interfering radar.

(A color version of this figure is available in the online journal.)

that passed our initial on-off-on test, but were ruled out as interference based on their similar topocentric frequency and modulation. Figure 5 shows two candidate signals detected at different topocentric frequencies, but that were ruled out as interference based on their similar bandwidths and modulation.

\subsection{Sensitivity}

From the radiometer equation, the minimum detectable flux, $F_{i}$, of narrow-band emission detected in a single polarization is given by ${ }^{5}$ :

$$
F_{i}=\sigma_{\text {thresh }} S_{\text {sys }} \sqrt{\frac{\Delta b}{t}}
$$

\footnotetext{
5 Assuming the intrinsic received emission width is $<\Delta b$, the spectral channel bandwidth.
}

Where $\sigma_{\text {thresh }}$ is the signal/noise threshold, $S_{\text {sys }}$ is the system equivalent flux density (SEFD) of the receiving telescope, $\Delta b$ is the spectral channel bandwidth and $t$ the integration time. Assuming a flat 10 Jy SEFD for the GBT's $L$-band receiver, a characteristic sensitivity for the observations presented here is $\sim 2 \times 10^{-23} \mathrm{erg} \mathrm{s}^{-1} \mathrm{~cm}^{-2}$ or $\sim 3 \mathrm{Jy}$ across a $0.75 \mathrm{~Hz}$ channel. A useful fiducial for considering the detectability of an extraterrestrial technology at radio wavelengths is the luminosity of the most powerful radio transmitter on Earth, the Arecibo Planetary Radar. Arecibo hosts two radar systems, a $430 \mathrm{MHz}$ system capable of pulsed operation at $\sim 2.5 \mathrm{MW}$ peak for a $\sim 5 \%$ duty cycle and a $2380 \mathrm{MHz}$ system producing $\sim 1 \mathrm{MW}$ continuous power. The equivalent isotropically radiated power (EIRP) of the higher frequency system, approaching $20 \mathrm{TW}$, is the larger of the two, owing to the $v^{2}$ gain improvement. We consider 


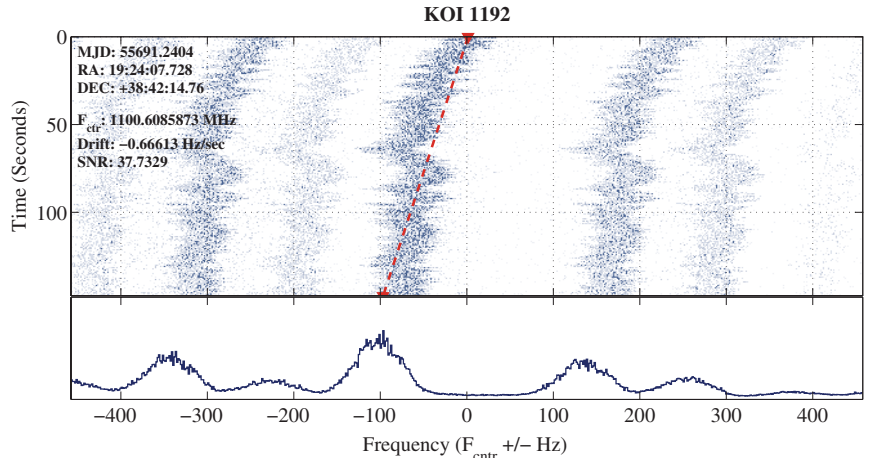

(a)

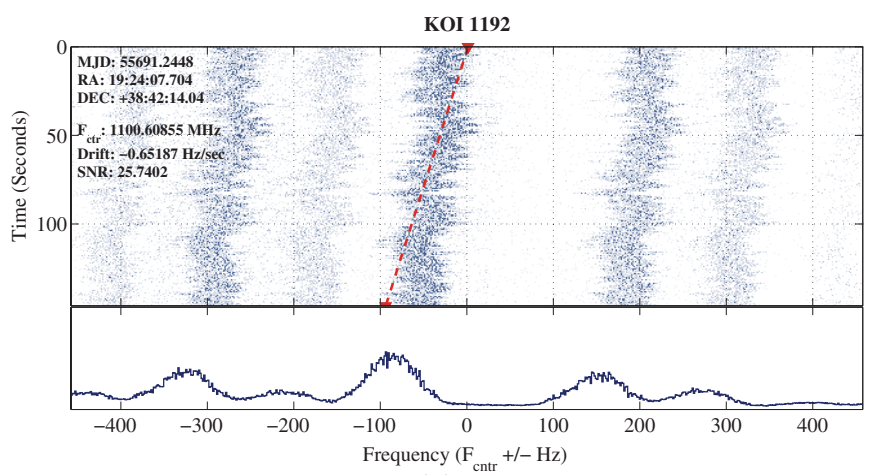

(b)

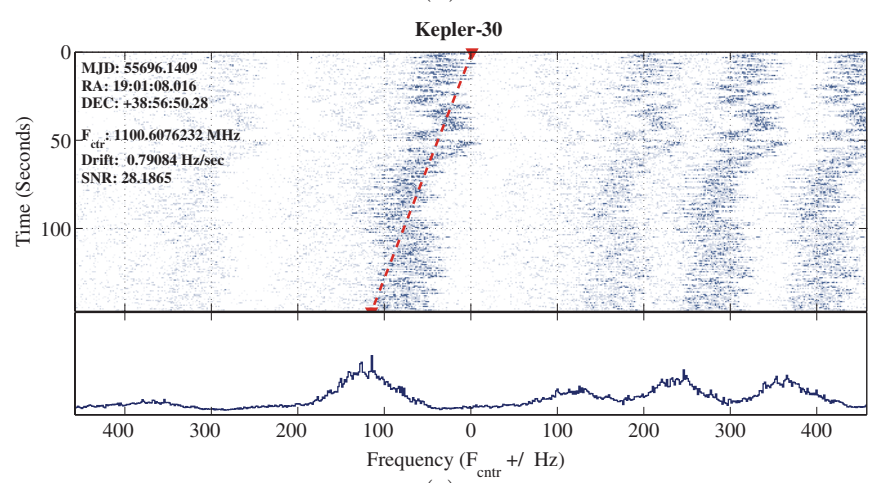

(c)

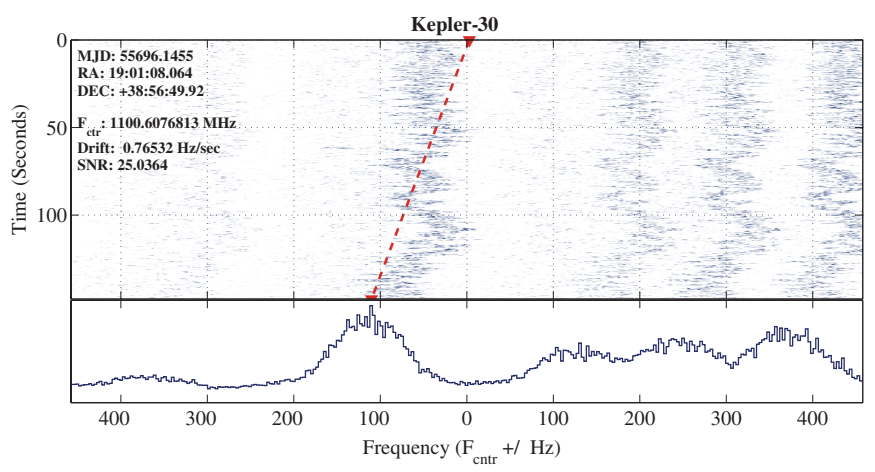

(d)

Figure 4. Waterfall plots showing narrow band emissions, all of which were determined to be interference based on similar topocentric frequency and modulation. The upper portion of each panel, in blue, shows intensity as a function of topocentric frequency and time and the lower portion of each panel shows a "Doppler-corrected spectrum"-a power spectrum for the entire observation formed by summing consecutive spectra at the drift rate indicated by the red diagonal. Panels (a) and (b) show detections of the interferer during two pointings on KOI 1192 separated by $\sim 380$ s. Panels (c) and (d) show detections of a very similar interferer approximately 5 days later during two pointings on Kepler-30.

(A color version of this figure is available in the online journal.)

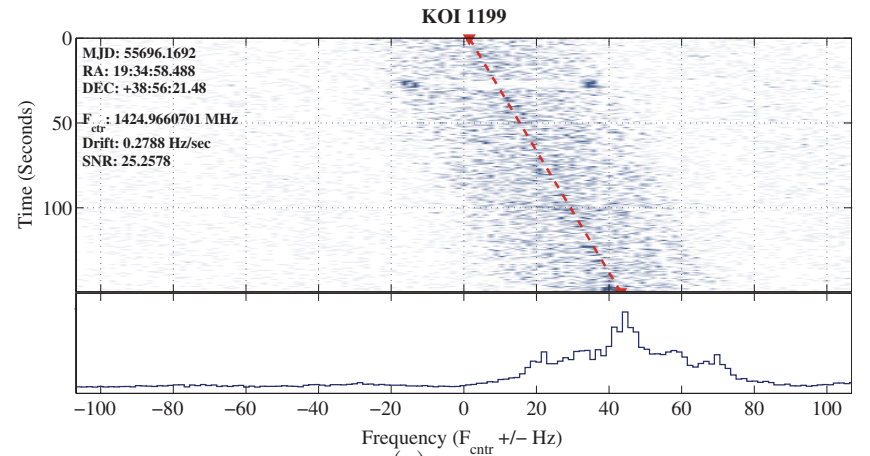

(a)

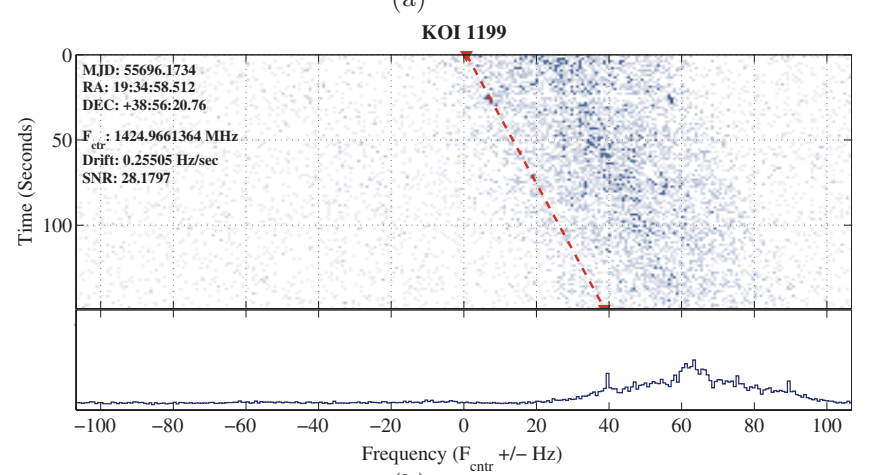

(b)

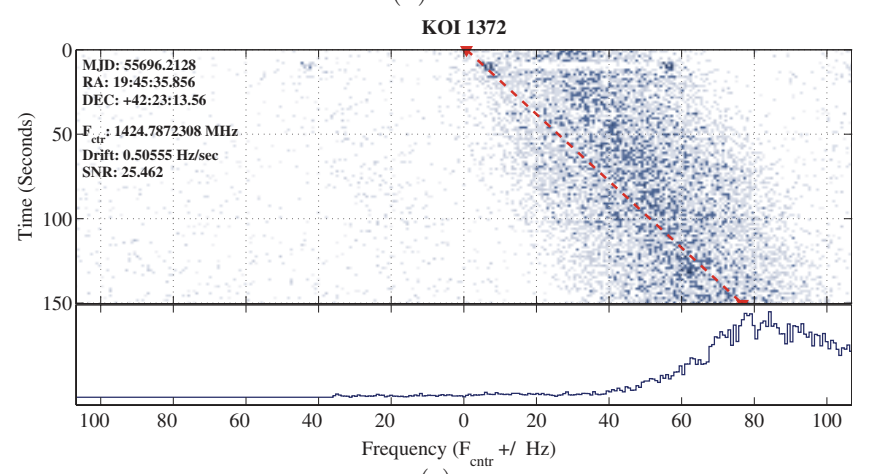

(c)

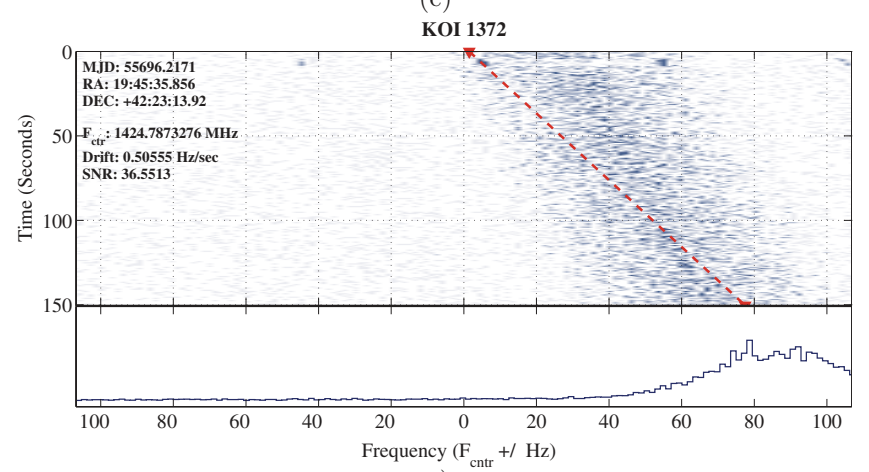

(d)

Figure 5. Waterfall plots showing narrow band emissions, all of which were determined to be interference based on similar bandwidth and modulation. See Figure 4 caption for plot descriptions. Panels (a) and (b) show detections of the interferer during two pointings on KOI 1199 separated by $\sim 360 \mathrm{~s}$. Panels (c) and (d) show detections of a very similar interferer approximately $1 \mathrm{hr}$ later during two pointings on KOI 1372.

(A color version of this figure is available in the online journal.)

this luminosity value $L_{\mathrm{AO}} \approx 2 \times 10^{20} \mathrm{erg} \mathrm{s}^{-1}$ to be approximately equal to the best-case radio emission from an Earth-level technology. Coincidently, $L_{\mathrm{AO}}$ is approximately the same as the current total average power used by all humans on the planet Earth (Gruenspecht 2010). At $0.5 \mathrm{kpc}$, a $1 L_{\mathrm{AO}}$ transmitter 


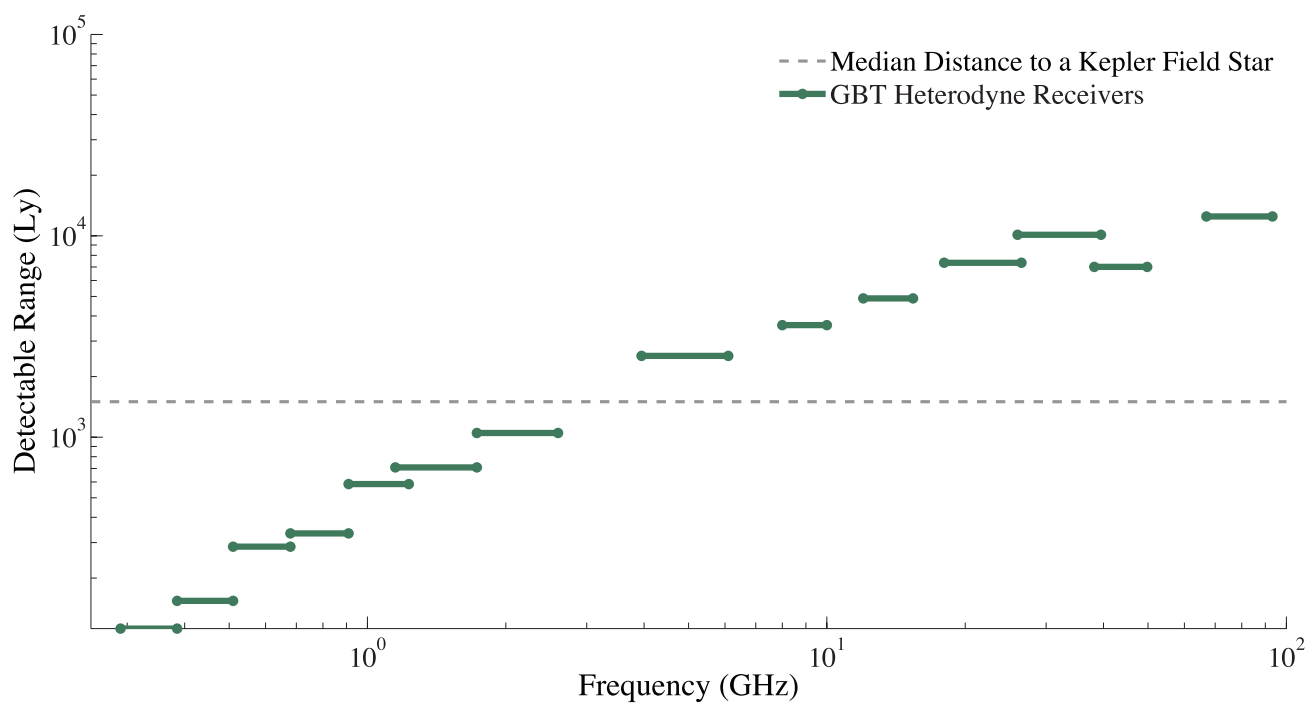

Figure 6. The range at which a transmitter similar to the Arecibo Planetary Radar $\left(\sim 5 \times 10^{13} \mathrm{erg} \mathrm{s}^{-1}\right.$ transmitted through a $305 \mathrm{~m}$ parabolic reflector) could be detected using the parameters of this experiment ( $150 \mathrm{~s}$ integrations, $0.75 \mathrm{~Hz}$ channelization) applied to all heterodyne receivers at the GBT.

(A color version of this figure is available in the online journal.)

beamed in the direction of Earth would have a total flux of about $10^{-24} \mathrm{erg} \mathrm{s}^{-1} \mathrm{~cm}^{-2}$, placing our detectable limit for this range at $\sim 8 L_{\mathrm{AO}}$. Table 3 details total on-source times and sensitivities for all observed sources.

Figure 6 shows the range at which a transmitter similar to the Arecibo Planetary Radar $\left(\sim 5 \times 10^{13} \mathrm{erg} \mathrm{s}^{-1}\right.$ transmitted through a $305 \mathrm{~m}$ parabolic reflector) could be detected using the parameters of this experiment $(150 \mathrm{~s}$ integrations, $0.75 \mathrm{~Hz}$ channelization) applied to all heterodyne receivers at the GBT. These limits also apply to an intrinsically uncertainty-limited broadband pulse having approximately 1000 times the total radiated energy, broadened assuming the "NE2001" ISM model (Cordes \& Lazio 2002) to $t=0.17 \mu$ s with pulse bandwidth $=$ $800 \mathrm{MHz}$ centered on our observing band. Here we have used system temperature and gain values from the GBT Proposer's Guide, neglected the galactic synchrotron background and for frequencies above $15 \mathrm{GHz}$ we assume a $50 \%$ weather quantile. We have assumed a $25 \sigma$ detection threshold, as was used in the analysis described here. The approximate median distance to a Kepler catalog star is also indicated. Although Figure 6 suggests higher frequencies might be preferred, again owing to the transmitter gain improvement, the additional scheduling difficulties due to weather constraints and pointing correction overhead make lower frequency observations more tractable at present.

We use the Arecibo Planetary Radar example simply as a point of reference. While this transmitter is highly directional and the probability of interception is thus fairly low, observing systems in which the ecliptic plane is viewed edge-on increases the probability of detecting a radar used for local planetary system ranging and imaging. If we assume that an exo-Arecibo has a duty cycle similar to Earth's, a characteristic ecliptic $\left( \pm 5^{\circ}\right)$ illumination of about $100 \mathrm{hr}$ year $^{-1}$ (P. Perillat 2012, private communication), the overall probability of being in the radar beam during an observation is $\sim 2 \times 10^{-8}$. While this figure is indeed low, it represents an order of magnitude improvement over an isotropic assumption.

\section{DISCUSSION AND SUMMARY}

Our search of 104 KOIs identified no evidence of advanced technology indicative of intelligent life. If we assume a low false positive rate for KOIs, in the simplest terms this result indicates that fewer than $\sim 1 \%$ of transiting exoplanet systems are radio loud in narrow-band emission between 1 and $2 \mathrm{GHz}$ at the $\sim 8 L_{\mathrm{AO}}$ level. If we take the orbital inclination requirement for detection to be $\pm 5^{\circ}$ and conservatively estimate the total fraction of FGK stars hosting planets of any type to be $\sim 15 \%$ (Marcy $\&$ Howard 2011), we estimate that fewer than $\sim 10^{-4}$ FGK stars host civilizations detectable via orbital plane narrow-band radio emission in the same band and luminosity. For the GBT, this implies a surface density of $<\sim 5 \times 10^{-2} \mathrm{deg}^{-2}$ detectable sources. For the upcoming Square Kilometer Array, a facility that will be perhaps 100 times more sensitive than the GBT, the similar surface density of detectable sources is $<\sim 100 \mathrm{deg}^{-2}$ ( $l=0, b=0$; Robin et al. 2003).

Although the observations described here were part of a campaign targeting specific KOIs, the size of the telescope beam probed a much larger population of stars at a concomitantly higher luminosity limit. When probing advanced technology luminosities that represent a reasonable extrapolation of terrestrial technology, i.e., $\approx$ Kardashev type I (Kardashev 1964), describing the target population and quantifying limits based on number of Sun-like stars or number of Earth-like planets is quite logical. However, when we begin to probe luminosities (and energy usage) that are many orders of magnitude larger than Earth's, our uncertainty in the bounds of life in general render these measures inadequate. For large luminosities, total stellar mass is a much more useful measure of the amount of energy-delivering capacity of a surveyed area. Integrating the GBT's beam out to and encompassing the Milky Way's halo stars (Gnedin et al. 2010), a characteristic total mass is $\sim 5 \times 10^{3} M_{\odot}$. At $80 \mathrm{kpc}$, our sensitivity equates to an EIRP limit of $\sim 10^{5} L_{\mathrm{AO}}$, or approximately an order of magnitude larger than the total solar insolation incident on Earth. A civilization capable of truly isotropic emission at these power levels would likely be capable of harnessing vastly greater amounts of energy from their parent sun than incident on their home planet, and thus would be approaching the Kardashev type II class. Taking our 86 observations as independent samples of a $\sim 5 \times 10^{3} M_{\odot}$ column, we estimate the number of $1-2 \mathrm{GHz}$ narrow-band-radio-loud Kardashev type II civilizations in the Milky Way to be $<10^{-6} M_{\odot}^{-1}$. 
Table 3

Kepler Field Targeted Observations 2011 February-April

\begin{tabular}{|c|c|c|c|c|c|c|c|c|c|c|c|c|c|c|}
\hline \multirow[t]{2}{*}{ Objects $^{\mathrm{a}}$} & \multicolumn{2}{|c|}{$\begin{array}{c}\text { Band } 0 \\
1.1-1.2 \mathrm{GHz}\end{array}$} & \multicolumn{2}{|c|}{$\begin{array}{c}\text { Band } 2^{\mathrm{b}} \\
1.33-1.4 \mathrm{GHz}\end{array}$} & \multicolumn{2}{|c|}{$\begin{array}{c}\text { Band } 3 \\
1.4-1.5 \mathrm{GHz} \\
\end{array}$} & \multicolumn{2}{|c|}{$\begin{array}{c}\text { Band } 4 \\
1.5-1.6 \mathrm{GHz} \\
\end{array}$} & \multicolumn{2}{|c|}{$\begin{array}{c}\text { Band } 5 \\
1.6-1.7 \mathrm{GHz} \\
\end{array}$} & \multicolumn{2}{|c|}{$\begin{array}{c}\text { Band } 6 \\
1.7-1.8 \mathrm{GHz} \\
\end{array}$} & \multicolumn{2}{|c|}{$\begin{array}{c}\text { Band } 7 \\
1.8-1.9 \mathrm{GHz}\end{array}$} \\
\hline & $\begin{array}{l}T_{\text {total }} \\
(\mathrm{s})\end{array}$ & $\begin{array}{c}S_{\text {peak }} \mathrm{c}^{-2} \\
\left(\mathrm{erg} \mathrm{s}^{-1} \mathrm{~cm}^{-2}\right)^{\mathrm{d}}\end{array}$ & $\begin{array}{c}T_{\text {total }} \\
(\mathrm{s})\end{array}$ & $\begin{array}{c}S_{\text {peak }} \\
\left(\mathrm{erg} \mathrm{s}^{-1} \mathrm{~cm}^{-2}\right)\end{array}$ & $\begin{array}{c}T_{\text {total }} \\
(\mathrm{s})\end{array}$ & $\begin{array}{c}S_{\text {peak }} \\
\left(\mathrm{erg} \mathrm{s}^{-1} \mathrm{~cm}^{-2}\right)\end{array}$ & $\begin{array}{c}T_{\text {total }} \\
(\mathrm{s})\end{array}$ & $\begin{array}{c}S_{\text {peak }} \\
\left(\mathrm{erg} \mathrm{s}^{-1} \mathrm{~cm}^{-2}\right)\end{array}$ & $\begin{array}{l}T_{\text {total }} \\
\text { (s) }\end{array}$ & $\begin{array}{c}S_{\text {peak }} \\
\left(\mathrm{erg} \mathrm{s}^{-1} \mathrm{~cm}^{-2}\right)\end{array}$ & $\begin{array}{c}T_{\text {total }} \\
(\mathrm{s})\end{array}$ & $\begin{array}{c}S_{\text {peak }} \\
\left(\mathrm{erg} \mathrm{s}^{-1} \mathrm{~cm}^{-2}\right)\end{array}$ & $\begin{array}{l}T_{\text {total }} \\
\text { (s) }\end{array}$ & $\begin{array}{c}S_{\text {peak }} \\
\left(\mathrm{erg} \mathrm{s}^{-1} \mathrm{~cm}^{-2}\right)\end{array}$ \\
\hline $\begin{array}{l}\text { Kepler-10 b } \\
\text { Kepler-10 c } \\
\end{array}$ & 296 & 1.78 & 301 & 1.76 & 303 & 1.76 & 305 & 1.75 & 307 & 1.75 & 309 & 1.74 & 311 & 1.73 \\
\hline $\begin{array}{l}\text { Kepler-11 b } \\
\text { Kepler-11 c } \\
\text { Kepler-11 d } \\
\text { Kepler-11 e } \\
\text { Kepler-11 f } \\
\text { Kepler-11 g } \\
\end{array}$ & 295 & 1.78 & 299 & 1.77 & 301 & 1.76 & 303 & 1.75 & 305 & 1.75 & 307 & 1.74 & 309 & 1.74 \\
\hline $\begin{array}{l}\text { Kepler-20 b } \\
\text { Kepler-20 c } \\
\text { Kepler-20 d } \\
\text { Kepler-20 e } \\
\text { Kepler-20 f }\end{array}$ & 295 & 1.78 & 299 & 1.77 & 301 & 1.76 & 303 & 1.76 & 305 & 1.75 & 308 & 1.75 & 309 & 1.74 \\
\hline Kepler-22 b & 295 & 1.78 & 300 & 1.77 & 302 & 1.76 & 304 & 1.76 & 306 & 1.75 & 308 & 1.75 & $\ldots$ & $\ldots$ \\
\hline $\begin{array}{l}\text { Kepler-30 b } \\
\text { Kepler-30 c } \\
\text { Kepler-30 d } \\
\end{array}$ & 295 & 1.78 & 300 & 1.77 & 302 & 1.76 & 304 & 1.75 & 306 & 1.75 & 308 & 1.74 & 310 & 1.74 \\
\hline $\begin{array}{l}\text { Kepler-31 b } \\
\text { Kepler-31 c } \\
\text { KOI 935.03 } \\
\text { KOI } 935.04\end{array}$ & $\ldots$ & $\ldots$ & 300 & 1.77 & $\cdots$ & $\ldots$ & $\cdots$ & $\cdots$ & $\cdots$ & $\ldots$ & $\cdots$ & $\cdots$ & $\cdots$ & $\cdots$ \\
\hline $\begin{array}{l}\text { Kepler-32 b } \\
\text { Kepler-32 c } \\
\text { KOI 952.03 } \\
\text { KOI } 952.04 \\
\end{array}$ & $\cdots$ & $\cdots$ & $\cdots$ & $\cdots$ & $\cdots$ & $\cdots$ & $\cdots$ & $\cdots$ & $\cdots$ & $\cdots$ & 302 & 1.75 & 305 & 1.74 \\
\hline KOI 51.01 & 293 & 1.78 & 297 & 1.77 & 300 & 1.77 & 302 & 1.76 & 304 & 1.75 & 306 & 1.75 & 308 & 1.74 \\
\hline $\begin{array}{l}\text { KOI } 111.01 \\
\text { KOI } 111.02 \\
\text { KOI } 111.03 \\
\end{array}$ & $\ldots$ & $\ldots$ & $\ldots$ & $\ldots$ & 301 & 1.76 & 303 & 1.76 & 305 & 1.75 & 307 & 1.75 & 309 & 1.74 \\
\hline KOI 113.01 & 293 & 1.78 & 298 & 1.77 & 300 & 1.77 & 302 & 1.76 & 304 & 1.75 & 306 & 1.75 & 308 & 1.74 \\
\hline KOI 174.01 & 293 & 1.79 & 298 & 1.77 & 300 & 1.77 & 302 & 1.76 & 304 & 1.76 & 306 & 1.75 & 308 & 1.75 \\
\hline KOI 211.01 & 295 & 1.78 & 299 & 1.77 & $\ldots$ & $\ldots$ & $\ldots$ & $\ldots$ & $\ldots$ & $\ldots$ & $\ldots$ & $\ldots$ & 306 & 1.74 \\
\hline $\begin{array}{l}\text { KOI } 260.01 \\
\text { KOI } 260.02 \\
\end{array}$ & 295 & 1.78 & 299 & 1.77 & 301 & 1.76 & 303 & 1.76 & 306 & 1.75 & 308 & 1.75 & 310 & 1.74 \\
\hline $\begin{array}{l}\text { KOI } 314.01 \\
\text { KOI } 314.02 \\
\text { KOI } 314.03 \\
\end{array}$ & 295 & 1.78 & 299 & 1.77 & 301 & 1.76 & 303 & 1.76 & 306 & 1.75 & 308 & 1.75 & 309 & 1.74 \\
\hline $\begin{array}{l}\text { KOI } 351.01 \\
\text { KOI } 351.02 \\
\text { KOI } 351.03\end{array}$ & 295 & 1.78 & 299 & 1.77 & 301 & 1.76 & 303 & 1.76 & 305 & 1.75 & 307 & 1.74 & 309 & 1.74 \\
\hline
\end{tabular}


Table 3

(Continued)

\begin{tabular}{|c|c|c|c|c|c|c|c|c|c|c|c|c|c|c|}
\hline \multirow[t]{2}{*}{ Objects $^{\mathrm{a}}$} & \multicolumn{2}{|c|}{$\begin{array}{c}\text { Band } 0 \\
1.1-1.2 \mathrm{GHz} \\
\end{array}$} & \multicolumn{2}{|c|}{$\begin{array}{c}\text { Band } 2^{\mathrm{b}} \\
1.33-1.4 \mathrm{GHz}\end{array}$} & \multicolumn{2}{|c|}{$\begin{array}{c}\text { Band 3 } \\
1.4-1.5 \mathrm{GHz} \\
\end{array}$} & \multicolumn{2}{|c|}{$\begin{array}{c}\text { Band } 4 \\
1.5-1.6 \mathrm{GHz} \\
\end{array}$} & \multicolumn{2}{|c|}{$\begin{array}{c}\text { Band 5 } \\
1.6-1.7 \mathrm{GHz} \\
\end{array}$} & \multicolumn{2}{|c|}{$\begin{array}{c}\text { Band } 6 \\
1.7-1.8 \mathrm{GHz} \\
\end{array}$} & \multicolumn{2}{|c|}{$\begin{array}{c}\text { Band } 7 \\
1.8-1.9 \mathrm{GHz} \\
\end{array}$} \\
\hline & $\begin{array}{c}T_{\text {total }} \\
(\mathrm{s})\end{array}$ & $\begin{array}{c}S_{\text {peak }}{ }^{\mathrm{c}} \\
\left(\mathrm{erg} \mathrm{s}^{-1} \mathrm{~cm}^{-2}\right)^{\mathrm{d}} \\
\end{array}$ & $\begin{array}{c}T_{\text {total }} \\
(\mathrm{s})\end{array}$ & $\begin{array}{c}S_{\text {peak }} \\
\left(\mathrm{erg} \mathrm{s}^{-1} \mathrm{~cm}^{-2}\right) \\
\end{array}$ & $\begin{array}{l}T_{\text {total }} \\
(\mathrm{s})\end{array}$ & $\begin{array}{c}S_{\text {peak }} \\
\left(\mathrm{erg} \mathrm{s}^{-1} \mathrm{~cm}^{-2}\right) \\
\end{array}$ & $\begin{array}{c}T_{\text {total }} \\
(\mathrm{s})\end{array}$ & $\begin{array}{c}S_{\text {peak }} \\
\left(\mathrm{erg} \mathrm{s}^{-1} \mathrm{~cm}^{-2}\right) \\
\end{array}$ & $\begin{array}{l}T_{\text {total }} \\
(\mathrm{s})\end{array}$ & $\begin{array}{c}S_{\text {peak }} \\
\left(\mathrm{erg} \mathrm{s}^{-1} \mathrm{~cm}^{-2}\right)\end{array}$ & $\begin{array}{c}T_{\text {total }} \\
(\mathrm{s})\end{array}$ & $\begin{array}{c}S_{\text {peak }} \\
\left(\mathrm{erg} \mathrm{s}^{-1} \mathrm{~cm}^{-2}\right)\end{array}$ & $\begin{array}{c}T_{\text {total }} \\
(\mathrm{s})\end{array}$ & $\begin{array}{c}S_{\text {peak }} \\
\left(\mathrm{erg} \mathrm{s}^{-1} \mathrm{~cm}^{-2}\right) \\
\end{array}$ \\
\hline KOI 365.01 & $\ldots$ & $\ldots$ & 297 & 1.78 & $\ldots$ & $\ldots$ & $\ldots$ & $\ldots$ & $\ldots$ & $\ldots$ & 304 & 1.75 & 306 & 1.75 \\
\hline KOI 372.01 & 295 & 1.78 & 300 & 1.77 & 302 & 1.76 & 304 & 1.75 & 306 & 1.75 & 308 & 1.74 & 310 & 1.74 \\
\hline KOI 374.01 & $\ldots$ & $\ldots$ & $\ldots$ & $\ldots$ & $\ldots$ & $\ldots$ & $\ldots$ & $\ldots$ & 302 & 1.75 & 304 & 1.75 & 306 & 1.74 \\
\hline KOI 375.01 & $\ldots$ & $\ldots$ & $\ldots$ & $\ldots$ & $\ldots$ & $\ldots$ & $\ldots$ & $\ldots$ & $\ldots$ & $\ldots$ & 304 & 1.75 & 306 & 1.74 \\
\hline $\begin{array}{l}\text { KOI } 386.01 \\
\text { KOI } 386.02 \\
\end{array}$ & 296 & 1.78 & 301 & 1.77 & 303 & 1.76 & 305 & 1.75 & 307 & 1.75 & 309 & 1.74 & 311 & 1.74 \\
\hline $\begin{array}{l}\text { KOI } 401.01 \\
\text { KOI } 401.02 \\
\end{array}$ & 296 & 1.78 & 301 & 1.76 & 303 & 1.76 & 289 & 1.79 & 307 & 1.75 & 309 & 1.74 & 311 & 1.73 \\
\hline $\begin{array}{l}\text { KOI } 416.01 \\
\text { KOI } 416.02 \\
\end{array}$ & 297 & 1.78 & 301 & 1.77 & 603 & 1.76 & 607 & 1.75 & 612 & 1.75 & 616 & 1.74 & 620 & 1.73 \\
\hline KOI 422.01 & $\ldots$ & $\ldots$ & $\ldots$ & $\ldots$ & $\ldots$ & $\ldots$ & $\ldots$ & $\ldots$ & 305 & 1.75 & 307 & 1.75 & 310 & 1.74 \\
\hline $\begin{array}{l}\text { KOI } 433.01 \\
\text { KOI } 433.02\end{array}$ & 294 & 1.78 & 299 & 1.77 & 301 & 1.76 & 303 & 1.76 & 305 & 1.75 & 307 & 1.75 & 309 & 1.74 \\
\hline $\begin{array}{l}\text { KOI } 448.01 \\
\text { KOI } 448.02 \\
\end{array}$ & 295 & 1.78 & 299 & 1.77 & 301 & 1.77 & 303 & 1.76 & 305 & 1.75 & 307 & 1.75 & 309 & 1.74 \\
\hline KOI 465.01 & $\ldots$ & $\ldots$ & 299 & 1.77 & $\ldots$ & $\ldots$ & $\ldots$ & $\ldots$ & $\ldots$ & $\ldots$ & $\ldots$ & $\ldots$ & $\ldots$ & $\ldots$ \\
\hline $\begin{array}{l}\text { KOI } 500.01 \\
\text { KOI } 500.02 \\
\text { KOI } 500.03 \\
\text { KOI } 500.04 \\
\text { KOI } 500.05 \\
\end{array}$ & 295 & 1.78 & 300 & 1.77 & 302 & 1.76 & 304 & 1.75 & 306 & 1.75 & 308 & 1.74 & 310 & 1.74 \\
\hline KOI 536.01 & 294 & 1.78 & 299 & 1.77 & $\ldots$ & $\ldots$ & $\ldots$ & $\ldots$ & $\ldots$ & $\ldots$ & $\ldots$ & $\ldots$ & $\ldots$ & $\ldots$ \\
\hline $\begin{array}{l}\text { KOI } 542.01 \\
\text { KOI } 542.02 \\
\end{array}$ & $\ldots$ & $\ldots$ & 300 & 1.76 & $\ldots$ & $\ldots$ & 303 & 1.75 & 305 & 1.75 & 307 & 1.74 & 309 & 1.74 \\
\hline $\begin{array}{l}\text { KOI } 555.01 \\
\text { KOI } 555.02 \\
\end{array}$ & 295 & 1.78 & 299 & 1.77 & 301 & 1.76 & 294 & 1.78 & 306 & 1.75 & 308 & 1.75 & $\ldots$ & $\ldots$ \\
\hline $\begin{array}{l}\text { KOI } 564.01 \\
\text { KOI } 564.02 \\
\end{array}$ & $\ldots$ & $\ldots$ & $\ldots$ & $\ldots$ & 300 & 1.76 & 287 & 1.77 & 304 & 1.75 & 306 & 1.75 & 308 & 1.74 \\
\hline $\begin{array}{l}\text { KOI } 590.01 \\
\text { KOI } 590.02 \\
\end{array}$ & 295 & 1.78 & 299 & 1.77 & $\ldots$ & $\ldots$ & $\ldots$ & $\ldots$ & $\cdots$ & $\ldots$ & 308 & 1.75 & 310 & 1.74 \\
\hline KOI 618.01 & $\ldots$ & $\ldots$ & $\ldots$ & $\ldots$ & $\ldots$ & $\ldots$ & $\ldots$ & $\ldots$ & $\ldots$ & $\ldots$ & 303 & 1.75 & 305 & 1.75 \\
\hline KOI 622.01 & $\ldots$ & $\ldots$ & $\ldots$ & $\ldots$ & $\ldots$ & $\ldots$ & $\ldots$ & $\ldots$ & $\ldots$ & $\ldots$ & 301 & 1.75 & 304 & 1.75 \\
\hline KOI 682.01 & 295 & 1.78 & 599 & 1.77 & 302 & 1.76 & 304 & 1.75 & 306 & 1.75 & 308 & 1.74 & 310 & 1.74 \\
\hline KOI 683.01 & 296 & 1.78 & 300 & 1.77 & 302 & 1.76 & 304 & 1.75 & 306 & 1.75 & 308 & 1.74 & 310 & 1.74 \\
\hline KOI 698.01 & $\ldots$ & $\ldots$ & 299 & 1.77 & $\ldots$ & $\ldots$ & $\ldots$ & $\ldots$ & $\ldots$ & $\ldots$ & $\ldots$ & $\ldots$ & $\ldots$ & $\ldots$ \\
\hline
\end{tabular}


Table 3

(Continued)

\begin{tabular}{|c|c|c|c|c|c|c|c|c|c|c|c|c|c|c|}
\hline \multirow[t]{2}{*}{ Objects $^{\mathrm{a}}$} & \multicolumn{2}{|c|}{$\begin{array}{c}\text { Band } 0 \\
1.1-1.2 \mathrm{GHz}\end{array}$} & \multicolumn{2}{|c|}{$\begin{array}{c}\text { Band } 2^{\mathrm{b}} \\
1.33-1.4 \mathrm{GHz}\end{array}$} & \multicolumn{2}{|c|}{$\begin{array}{c}\text { Band 3 } \\
1.4-1.5 \mathrm{GHz}\end{array}$} & \multicolumn{2}{|c|}{$\begin{array}{c}\text { Band } 4 \\
1.5-1.6 \mathrm{GHz}\end{array}$} & \multicolumn{2}{|c|}{$\begin{array}{c}\text { Band } 5 \\
1.6-1.7 \mathrm{GHz}\end{array}$} & \multicolumn{2}{|c|}{$\begin{array}{c}\text { Band } 6 \\
1.7-1.8 \mathrm{GHz}\end{array}$} & \multicolumn{2}{|c|}{$\begin{array}{c}\text { Band } 7 \\
1.8-1.9 \mathrm{GHz}\end{array}$} \\
\hline & $\begin{array}{c}T_{\text {total }} \\
(\mathrm{s})\end{array}$ & $\begin{array}{c}S_{\text {peak }}{ }^{\mathrm{c}} \\
\left(\mathrm{erg} \mathrm{s}^{-1} \mathrm{~cm}^{-2}\right)^{\mathrm{d}}\end{array}$ & $\begin{array}{l}T_{\text {total }} \\
\text { (s) }\end{array}$ & $\begin{array}{c}S_{\text {peak }} \\
\left(\mathrm{erg} \mathrm{s}^{-1} \mathrm{~cm}^{-2}\right)\end{array}$ & $\begin{array}{c}T_{\text {total }} \\
\text { (s) }\end{array}$ & $\begin{array}{c}S_{\text {peak }} \\
\left(\mathrm{erg} \mathrm{s}^{-1} \mathrm{~cm}^{-2}\right)\end{array}$ & $\begin{array}{l}T_{\text {total }} \\
\text { (s) }\end{array}$ & $\begin{array}{c}S_{\text {peak }} \\
\left(\mathrm{erg} \mathrm{s}^{-1} \mathrm{~cm}^{-2}\right)\end{array}$ & $\begin{array}{c}T_{\text {total }} \\
(\mathrm{s})\end{array}$ & $\begin{array}{c}S_{\text {peak }} \\
\left(\mathrm{erg} \mathrm{s}^{-1} \mathrm{~cm}^{-2}\right)\end{array}$ & $\begin{array}{l}T_{\text {total }} \\
\text { (s) }\end{array}$ & $\begin{array}{c}S_{\text {peak }} \\
\left(\mathrm{erg} \mathrm{s}^{-1} \mathrm{~cm}^{-2}\right)\end{array}$ & $\begin{array}{c}T_{\text {total }} \\
(\mathrm{s})\end{array}$ & $\begin{array}{c}S_{\text {peak }} \\
\left(\mathrm{erg} \mathrm{s}^{-1} \mathrm{~cm}^{-2}\right)\end{array}$ \\
\hline $\begin{array}{l}\text { KOI } 701.01 \\
\text { KOI } 701.02 \\
\text { KOI } 701.03 \\
\end{array}$ & $\ldots$ & $\ldots$ & $\ldots$ & $\ldots$ & $\ldots$ & $\ldots$ & $\ldots$ & $\ldots$ & 301 & 1.75 & 303 & 1.75 & 305 & 1.74 \\
\hline $\begin{array}{l}\text { KOI } 711.01 \\
\text { KOI } 711.02 \\
\text { KOI } 711.03 \\
\end{array}$ & $\ldots$ & $\ldots$ & $\ldots$ & $\ldots$ & 302 & 1.76 & 304 & 1.76 & 306 & 1.75 & 308 & 1.75 & 310 & 1.74 \\
\hline KOI 741.01 & $\ldots$ & $\ldots$ & $\ldots$ & $\ldots$ & $\ldots$ & $\ldots$ & $\ldots$ & $\ldots$ & $\ldots$ & $\ldots$ & 303 & 1.75 & 305 & 1.75 \\
\hline $\begin{array}{l}\text { KOI } 812.01 \\
\text { KOI } 812.02 \\
\text { KOI } 812.03 \\
\text { KOI } 812.04 \\
\end{array}$ & 296 & 1.78 & 301 & 1.76 & 303 & 1.76 & 295 & 1.78 & 307 & 1.75 & 309 & 1.74 & 311 & 1.73 \\
\hline $\begin{array}{l}\text { KOI } 817.01 \\
\text { KOI } 817.02 \\
\end{array}$ & 296 & 1.78 & 300 & 1.76 & 302 & 1.76 & 292 & 1.78 & 307 & 1.75 & 309 & 1.74 & 311 & 1.73 \\
\hline KOI 826.01 & 296 & 1.78 & 300 & 1.77 & 302 & 1.76 & 295 & 1.76 & 306 & 1.75 & 308 & 1.74 & $\ldots$ & $\ldots$ \\
\hline KOI 847.01 & 294 & 1.78 & 298 & 1.77 & 301 & 1.77 & 303 & 1.76 & 305 & 1.75 & 307 & 1.75 & 309 & 1.74 \\
\hline KOI 854.01 & 295 & 1.78 & 299 & 1.77 & 301 & 1.76 & 304 & 1.76 & 306 & 1.75 & 308 & 1.75 & 310 & 1.74 \\
\hline KOI 882.01 & 294 & 1.78 & 299 & 1.77 & 301 & 1.76 & 303 & 1.76 & 305 & 1.75 & 307 & 1.75 & 309 & 1.74 \\
\hline KOI 892.01 & 295 & 1.78 & 299 & 1.77 & 301 & 1.76 & 303 & 1.76 & 306 & 1.75 & 308 & 1.75 & 309 & 1.74 \\
\hline KOI 902.01 & $\ldots$ & $\ldots$ & $\ldots$ & $\ldots$ & 299 & 1.76 & 301 & 1.76 & 303 & 1.75 & 305 & 1.75 & 308 & 1.74 \\
\hline KOI 947.01 & $\ldots$ & $\ldots$ & $\ldots$ & $\ldots$ & $\ldots$ & $\ldots$ & 294 & 1.77 & 311 & 1.72 & 313 & 1.72 & 315 & 1.71 \\
\hline KOI 974.01 & 294 & 1.78 & 299 & 1.77 & $\ldots$ & $\ldots$ & $\ldots$ & $\ldots$ & $\ldots$ & $\ldots$ & 304 & 1.75 & 306 & 1.75 \\
\hline $\begin{array}{l}\text { KOI } 986.01 \\
\text { KOI } 986.02 \\
\end{array}$ & 296 & 1.77 & 301 & 1.76 & 303 & 1.76 & 299 & 1.75 & 307 & 1.74 & 309 & 1.74 & 311 & 1.73 \\
\hline KOI 998.01 & 294 & 1.78 & 298 & 1.77 & 300 & 1.77 & 302 & 1.76 & 304 & 1.75 & 306 & 1.75 & 308 & 1.74 \\
\hline KOI 1010.01 & 294 & 1.78 & 298 & 1.77 & 300 & 1.77 & 302 & 1.76 & 304 & 1.75 & 306 & 1.75 & 308 & 1.74 \\
\hline KOI 1032.01 & 294 & 1.78 & 298 & 1.77 & 300 & 1.77 & 302 & 1.76 & 304 & 1.75 & 306 & 1.75 & 308 & 1.74 \\
\hline KOI 1099.01 & 296 & 1.78 & 301 & 1.76 & 303 & 1.76 & 305 & 1.75 & 307 & 1.75 & 309 & 1.74 & 311 & 1.73 \\
\hline $\begin{array}{l}\text { KOI } 1113.01 \\
\text { KOI } 1113.02\end{array}$ & 296 & 1.77 & 301 & 1.76 & 303 & 1.76 & 299 & 1.75 & 307 & 1.74 & 309 & 1.74 & 311 & 1.73 \\
\hline KOI 1118.01 & 296 & 1.78 & 301 & 1.76 & 303 & 1.76 & 305 & 1.75 & 307 & 1.75 & 309 & 1.74 & 311 & 1.73 \\
\hline KOI 1159.01 & $\ldots$ & $\ldots$ & $\ldots$ & $\ldots$ & $\ldots$ & $\ldots$ & $\ldots$ & $\ldots$ & $\ldots$ & $\ldots$ & 303 & 1.75 & 305 & 1.75 \\
\hline KOI 1162.01 & 296 & 1.78 & 300 & 1.77 & 302 & 1.76 & $\ldots$ & $\ldots$ & $\ldots$ & $\ldots$ & $\ldots$ & $\ldots$ & $\ldots$ & $\ldots$ \\
\hline KOI 1168.01 & $\ldots$ & $\ldots$ & 300 & 1.77 & 302 & 1.76 & $\ldots$ & $\ldots$ & $\ldots$ & $\ldots$ & $\ldots$ & $\ldots$ & $\ldots$ & $\ldots$ \\
\hline KOI 1192.01 & 294 & 1.78 & 298 & 1.77 & $\ldots$ & $\ldots$ & $\ldots$ & $\ldots$ & $\ldots$ & $\ldots$ & $\ldots$ & $\ldots$ & $\ldots$ & $\ldots$ \\
\hline
\end{tabular}


Table 3

(Continued)

\begin{tabular}{|c|c|c|c|c|c|c|c|c|c|c|c|c|c|c|}
\hline \multirow[t]{2}{*}{ Objects $^{\mathrm{a}}$} & \multicolumn{2}{|c|}{$\begin{array}{c}\text { Band } 0 \\
1.1-1.2 \mathrm{GHz} \\
\end{array}$} & \multicolumn{2}{|c|}{$\begin{array}{c}\text { Band } 2^{\mathrm{b}} \\
1.33-1.4 \mathrm{GHz}\end{array}$} & \multicolumn{2}{|c|}{$\begin{array}{c}\text { Band 3 } \\
1.4-1.5 \mathrm{GHz}\end{array}$} & \multicolumn{2}{|c|}{$\begin{array}{c}\text { Band } 4 \\
1.5-1.6 \mathrm{GHz} \\
\end{array}$} & \multicolumn{2}{|c|}{$\begin{array}{c}\text { Band 5 } \\
1.6-1.7 \mathrm{GHz}\end{array}$} & \multicolumn{2}{|c|}{$\begin{array}{c}\text { Band } 6 \\
1.7-1.8 \mathrm{GHz} \\
\end{array}$} & \multicolumn{2}{|c|}{$\begin{array}{c}\text { Band } 7 \\
1.8-1.9 \mathrm{GHz} \\
\end{array}$} \\
\hline & $\begin{array}{l}T_{\text {total }} \\
(\mathrm{s})\end{array}$ & $\begin{array}{c}S_{\text {peak }}{ }^{\mathrm{c}} \\
\left(\mathrm{erg} \mathrm{s}^{-1} \mathrm{~cm}^{-2}\right)^{\mathrm{d}}\end{array}$ & $\begin{array}{l}T_{\text {total }} \\
\text { (s) }\end{array}$ & $\begin{array}{c}S_{\text {peak }} \\
\left(\mathrm{erg} \mathrm{s}^{-1} \mathrm{~cm}^{-2}\right)\end{array}$ & $\begin{array}{l}T_{\text {total }} \\
(\mathrm{s})\end{array}$ & $\begin{array}{c}S_{\text {peak }} \\
\left(\mathrm{erg} \mathrm{s}^{-1} \mathrm{~cm}^{-2}\right)\end{array}$ & $\begin{array}{l}T_{\text {total }} \\
(\mathrm{s})\end{array}$ & $\begin{array}{c}S_{\text {peak }} \\
\left(\mathrm{erg} \mathrm{s}^{-1} \mathrm{~cm}^{-2}\right)\end{array}$ & $\begin{array}{l}T_{\text {total }} \\
(\mathrm{s})\end{array}$ & $\begin{array}{c}S_{\text {peak }} \\
\left(\mathrm{erg} \mathrm{s}^{-1} \mathrm{~cm}^{-2}\right)\end{array}$ & $\begin{array}{l}T_{\text {total }} \\
(\mathrm{s})\end{array}$ & $\begin{array}{c}S_{\text {peak }} \\
\left(\mathrm{erg} \mathrm{s}^{-1} \mathrm{~cm}^{-2}\right)\end{array}$ & $\begin{array}{l}T_{\text {total }} \\
(\mathrm{s})\end{array}$ & $\begin{array}{c}S_{\text {peak }} \\
\left(\mathrm{erg} \mathrm{s}^{-1} \mathrm{~cm}^{-2}\right)\end{array}$ \\
\hline KOI 1199.01 & 295 & 1.78 & 299 & 1.77 & 301 & 1.77 & 303 & 1.76 & 305 & 1.75 & 307 & 1.75 & 309 & 1.74 \\
\hline $\begin{array}{l}\text { KOI } 1203.01 \\
\text { KOI } 1203.02 \\
\text { KOI 1203.03 } \\
\end{array}$ & 295 & 1.78 & 299 & 1.77 & 301 & 1.76 & 303 & 1.76 & 305 & 1.75 & 307 & 1.75 & 309 & 1.74 \\
\hline KOI 1208.01 & 295 & 1.78 & 299 & 1.77 & 301 & 1.76 & 303 & 1.76 & 305 & 1.75 & 307 & 1.75 & 309 & 1.74 \\
\hline KOI 1210.01 & 295 & 1.78 & 299 & 1.77 & 301 & 1.76 & 303 & 1.76 & 305 & 1.75 & 307 & 1.75 & 309 & 1.74 \\
\hline KOI 1226.01 & 295 & 1.78 & 299 & 1.77 & 301 & 1.77 & 303 & 1.76 & 305 & 1.75 & 307 & 1.75 & 309 & 1.74 \\
\hline $\begin{array}{l}\text { KOI } 1261.01 \\
\text { KOI } 1261.02 \\
\end{array}$ & $\cdots$ & $\cdots$ & $\cdots$ & $\cdots$ & $\cdots$ & $\cdots$ & $\cdots$ & $\ldots$ & $\ldots$ & $\ldots$ & 307 & 1.75 & 309 & 1.74 \\
\hline KOI 1268.01 & 295 & 1.78 & 299 & 1.77 & 301 & 1.76 & 303 & 1.76 & 306 & 1.75 & 308 & 1.75 & 310 & 1.74 \\
\hline KOI 1302.01 & 292 & 1.79 & 296 & 1.78 & 298 & 1.77 & 300 & 1.76 & 303 & 1.76 & 305 & 1.75 & $\ldots$ & $\ldots$ \\
\hline KOI 1328.01 & 296 & 1.78 & 300 & 1.76 & 302 & 1.76 & 304 & 1.75 & 306 & 1.75 & 309 & 1.74 & 310 & 1.73 \\
\hline KOI 1355.01 & 297 & 1.78 & 599 & 1.77 & 603 & 1.76 & 600 & 1.75 & 611 & 1.75 & 616 & 1.74 & 620 & 1.74 \\
\hline $\begin{array}{l}\text { KOI } 1358.01 \\
\text { KOI } 1358.02 \\
\text { KOI } 1358.03 \\
\end{array}$ & 294 & 1.78 & 299 & 1.77 & 301 & 1.76 & 303 & 1.76 & 305 & 1.75 & 307 & 1.75 & 309 & 1.74 \\
\hline KOI 1361.01 & $\ldots$ & $\ldots$ & $\ldots$ & $\ldots$ & 302 & 1.76 & 295 & 1.78 & 306 & 1.75 & 308 & 1.75 & 310 & 1.74 \\
\hline KOI 1372.01 & 296 & 1.78 & 300 & 1.76 & 302 & 1.76 & 304 & 1.75 & 306 & 1.75 & 308 & 1.74 & 310 & 1.73 \\
\hline KOI 1375.01 & 295 & 1.78 & 300 & 1.77 & 302 & 1.76 & 304 & 1.76 & 306 & 1.75 & 308 & 1.75 & 309 & 1.74 \\
\hline KOI 1377.01 & 297 & 1.78 & 599 & 1.77 & 603 & 1.76 & 600 & 1.75 & 611 & 1.75 & 616 & 1.74 & 620 & 1.74 \\
\hline KOI 1379.01 & 297 & 1.78 & 599 & 1.77 & 603 & 1.76 & 600 & 1.75 & 611 & 1.75 & 616 & 1.74 & 620 & 1.74 \\
\hline KOI 1423.01 & $\ldots$ & $\ldots$ & $\ldots$ & $\ldots$ & $\ldots$ & $\ldots$ & 300 & 1.76 & 303 & 1.75 & $\ldots$ & $\ldots$ & $\ldots$ & $\ldots$ \\
\hline $\begin{array}{l}\text { KOI } 1426.01 \\
\text { KOI } 1426.02 \\
\text { KOI } 1426.03 \\
\end{array}$ & $\ldots$ & $\ldots$ & 300 & 1.77 & 302 & 1.76 & 304 & 1.76 & 306 & 1.75 & 308 & 1.75 & 310 & 1.74 \\
\hline KOI 1429.01 & $\ldots$ & $\ldots$ & $\ldots$ & $\ldots$ & $\ldots$ & $\ldots$ & 297 & 1.78 & 303 & 1.75 & 305 & 1.75 & 307 & 1.74 \\
\hline KOI 1463.01 & 297 & 1.78 & 301 & 1.77 & 303 & 1.76 & 305 & 1.75 & 307 & 1.75 & 309 & 1.74 & 615 & 1.74 \\
\hline KOI 1472.01 & $\ldots$ & $\ldots$ & $\ldots$ & $\ldots$ & $\ldots$ & $\ldots$ & 292 & 1.78 & 304 & 1.75 & 306 & 1.74 & 308 & 1.73 \\
\hline KOI 1478.01 & 295 & 1.78 & 299 & 1.77 & $\ldots$ & $\ldots$ & $\ldots$ & $\ldots$ & $\ldots$ & $\ldots$ & 304 & 1.74 & 306 & 1.74 \\
\hline $\begin{array}{l}\text { KOI } 1486.01 \\
\text { KOI } 1486.02 \\
\end{array}$ & 295 & 1.78 & 299 & 1.77 & 301 & 1.76 & 295 & 1.78 & 306 & 1.75 & 308 & 1.75 & 310 & 1.74 \\
\hline KOI 1503.01 & 296 & 1.78 & 300 & 1.77 & 302 & 1.76 & 304 & 1.76 & 306 & 1.75 & 308 & 1.75 & 310 & 1.74 \\
\hline KOI 1508.01 & $\ldots$ & $\ldots$ & $\ldots$ & $\ldots$ & $\ldots$ & $\ldots$ & 292 & 1.78 & 304 & 1.75 & 306 & 1.74 & 308 & 1.73 \\
\hline KOI 1527.01 & 295 & 1.78 & 299 & 1.77 & 301 & 1.76 & 303 & 1.76 & 305 & 1.75 & 308 & 1.75 & 309 & 1.74 \\
\hline
\end{tabular}


Table 3

(Continued)

\begin{tabular}{|c|c|c|c|c|c|c|c|c|c|c|c|c|c|c|}
\hline \multirow[t]{2}{*}{$\overline{\text { Objects }^{\mathrm{a}}}$} & \multicolumn{2}{|c|}{$\begin{array}{c}\text { Band } 0 \\
1.1-1.2 \mathrm{GHz}\end{array}$} & \multicolumn{2}{|c|}{$\begin{array}{c}\text { Band } 2^{\mathrm{b}} \\
1.33-1.4 \mathrm{GHz}\end{array}$} & \multicolumn{2}{|c|}{$\begin{array}{c}\text { Band 3 } \\
1.4-1.5 \mathrm{GHz}\end{array}$} & \multicolumn{2}{|c|}{$\begin{array}{c}\text { Band } 4 \\
1.5-1.6 \mathrm{GHz}\end{array}$} & \multicolumn{2}{|c|}{$\begin{array}{c}\text { Band 5 } \\
1.6-1.7 \mathrm{GHz}\end{array}$} & \multicolumn{2}{|c|}{$\begin{array}{c}\text { Band } 6 \\
1.7-1.8 \mathrm{GHz}\end{array}$} & \multicolumn{2}{|c|}{$\begin{array}{c}\text { Band } 7 \\
1.8-1.9 \mathrm{GHz}\end{array}$} \\
\hline & $\begin{array}{c}T_{\text {total }} \\
(\mathrm{s})\end{array}$ & $\begin{array}{c}S_{\text {peak }}{ }^{\mathrm{c}} \\
\left(\mathrm{erg} \mathrm{s}^{-1} \mathrm{~cm}^{-2}\right)^{\mathrm{d}}\end{array}$ & $\begin{array}{c}T_{\text {total }} \\
(\mathrm{s})\end{array}$ & $\begin{array}{c}S_{\text {peak }} \\
\left(\mathrm{erg} \mathrm{s}^{-1} \mathrm{~cm}^{-2}\right)\end{array}$ & $\begin{array}{l}T_{\text {total }} \\
(\mathrm{s})\end{array}$ & $\begin{array}{c}S_{\text {peak }} \\
\left(\mathrm{erg} \mathrm{s}^{-1} \mathrm{~cm}^{-2}\right)\end{array}$ & $\begin{array}{l}T_{\text {total }} \\
\text { (s) }\end{array}$ & $\begin{array}{c}S_{\text {peak }} \\
\left(\mathrm{erg} \mathrm{s}^{-1} \mathrm{~cm}^{-2}\right)\end{array}$ & $\begin{array}{l}T_{\text {total }} \\
\text { (s) }\end{array}$ & $\begin{array}{c}S_{\text {peak }} \\
\left(\mathrm{erg} \mathrm{s}^{-1} \mathrm{~cm}^{-2}\right)\end{array}$ & $\begin{array}{l}T_{\text {total }} \\
\text { (s) }\end{array}$ & $\begin{array}{c}S_{\text {peak }} \\
\left(\mathrm{erg} \mathrm{s}^{-1} \mathrm{~cm}^{-2}\right)\end{array}$ & $\begin{array}{l}T_{\text {total }} \\
\text { (s) }\end{array}$ & $\begin{array}{c}S_{\text {peak }} \\
\left(\mathrm{erg} \mathrm{s}^{-1} \mathrm{~cm}^{-2}\right)\end{array}$ \\
\hline KOI 1528.01 & $\ldots$ & $\ldots$ & $\ldots$ & $\ldots$ & $\ldots$ & $\ldots$ & 292 & 1.78 & 304 & 1.75 & 306 & 1.74 & 308 & 1.73 \\
\hline KOI 1535.01 & $\ldots$ & $\ldots$ & 300 & 1.76 & $\ldots$ & $\ldots$ & 303 & 1.75 & 305 & 1.75 & 307 & 1.74 & 309 & 1.74 \\
\hline KOI 1561.01 & 295 & 1.78 & 300 & 1.77 & 302 & 1.76 & 304 & 1.75 & 306 & 1.75 & 308 & 1.74 & 310 & 1.74 \\
\hline KOI 1564.01 & 296 & 1.78 & 300 & 1.77 & 302 & 1.76 & 295 & 1.76 & 306 & 1.75 & 308 & 1.74 & $\ldots$ & $\ldots$ \\
\hline KOI 1574.01 & 294 & 1.78 & 298 & 1.77 & 300 & 1.76 & 303 & 1.76 & 305 & 1.75 & 307 & 1.75 & 309 & 1.74 \\
\hline KOI 1582.01 & 295 & 1.78 & 299 & 1.77 & $\ldots$ & $\ldots$ & $\ldots$ & $\ldots$ & $\ldots$ & $\ldots$ & $\ldots$ & $\ldots$ & $\ldots$ & $\ldots$ \\
\hline $\begin{array}{l}\text { KOI } 1596.01 \\
\text { KOI } 1596.02\end{array}$ & 295 & 1.78 & $\ldots$ & $\ldots$ & $\ldots$ & $\ldots$ & $\ldots$ & $\ldots$ & $\ldots$ & $\ldots$ & 307 & 1.74 & 309 & 1.74 \\
\hline $\begin{array}{l}\text { KOI } 1598.01 \\
\text { KOI } 1598.02 \\
\text { KOI } 1598.03 \\
\end{array}$ & 293 & 1.78 & 297 & 1.77 & 299 & 1.76 & 301 & 1.76 & 303 & 1.75 & 306 & 1.75 & 308 & 1.74 \\
\hline KOI 1648.01 & $\ldots$ & $\ldots$ & $\ldots$ & $\ldots$ & $\ldots$ & $\ldots$ & 300 & 1.76 & 303 & 1.75 & $\ldots$ & $\ldots$ & $\ldots$ & $\ldots$ \\
\hline KOI 1749.01 & $\ldots$ & $\ldots$ & $\ldots$ & $\ldots$ & 300 & 1.76 & 287 & 1.77 & 304 & 1.75 & 306 & 1.75 & 308 & 1.74 \\
\hline KOI 1819.01 & $\ldots$ & $\ldots$ & $\ldots$ & $\ldots$ & 302 & 1.76 & 304 & 1.76 & 306 & 1.75 & 308 & 1.75 & 310 & 1.74 \\
\hline $\begin{array}{l}\text { KOI } 2248.01 \\
\text { KOI } 2248.02 \\
\text { KOI } 2248.03 \\
\text { KOI } 2248.04\end{array}$ & $\cdots$ & $\ldots$ & $\ldots$ & $\ldots$ & $\cdots$ & $\ldots$ & 297 & 1.78 & 303 & 1.75 & 305 & 1.75 & 307 & 1.74 \\
\hline KOI 2418.01 & 295 & 1.78 & $\ldots$ & $\ldots$ & $\ldots$ & $\ldots$ & $\ldots$ & $\ldots$ & $\ldots$ & $\ldots$ & 307 & 1.74 & 309 & 1.74 \\
\hline KOI 2493.01 & 294 & 1.78 & 298 & 1.77 & 300 & 1.76 & 303 & 1.76 & 305 & 1.75 & 307 & 1.75 & 309 & 1.74 \\
\hline $\begin{array}{l}\text { KOI } 2534.01 \\
\text { KOI } 2534.02\end{array}$ & 297 & 1.78 & 302 & 1.76 & 304 & 1.76 & 296 & 1.78 & 308 & 1.75 & 310 & 1.74 & 312 & 1.73 \\
\hline
\end{tabular}

\section{Notes.}

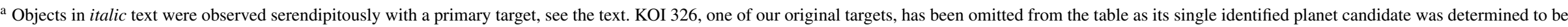
a false positive.

${ }^{\mathrm{b}}$ We exclude Band 1 here, as the band $1200-1330 \mathrm{MHz}$ was not searched due to the presence of a bandpass filter used to mitigate heavy aircraft radar interference contaminating this region.

${ }^{c}$ Peak sensitivity quoted for $0.75 \mathrm{~Hz}$ channelization.

$\mathrm{d} / 10^{-23}$. 
Ultimately, experiments such as the one described here seek to firmly determine the number of other intelligent, communicative civilizations outside of Earth. However, in placing limits on the presence of intelligent life in the galaxy, we must very carefully qualify our limits with respect to the limitations of our experiment. In particular, we can offer no argument that an advanced, intelligent civilization necessarily produces narrow-band radio emission, either intentional or otherwise. Thus we are probing only a potential subset of such civilizations, where the size of the subset is difficult to estimate. The search for extraterrestrial intelligence is still in its infancy, and there is much parameter space left to explore. The exponential growth in semiconductor technology over the last decades has been an incredible boon to SETI experiments, allowing orders of magnitude improvements in spectral coverage. Within the next decade, we will have the ability to examine significantly larger portions of the electromagnetic spectrum, including instantaneous analysis of the entire $10 \mathrm{GHz}$ of the terrestrial microwave window. In addition to radio searches, new technology will extend SETI into regions of the electromagnetic spectrum never before observed with high sensitivity (Siemion et al. 2011). Extending searches to encompass much larger classes of signals is crucial to producing robust and meaningful limits.

We thank John Ford and Scott Ransom for technical assistance during our observations and Gerry Harp for comments on an early draft of this manuscript. The work presented here was partially funded by NASA Exobiology Grant NNX09AN69G and donations from the Friends of Berkeley SETI and the Friends of SETI@home. We also acknowledge the financial and intellectual contributions of the students, faculty and sponsors of the Berkeley Wireless Research Center. This research used resources of the National Energy Research Scientific Computing Center, which is supported by the Office of Science of the U.S. Department of Energy under Contract No. DE-AC0205CH1123. A.P.V.S. gratefully acknowledges receipt of student observing support from the National Radio Astronomy Observatory. The National Radio Astronomy Observatory is a facility of the National Science Foundation operated under cooperative agreement by Associated Universities, Inc.

\section{REFERENCES}

Benford, J., Benford, G., \& Benford, D. 2008, arXiv:0810.3964v2 Borucki, W. J., Koch, D. G., \& Team, K. S. 2011, ApJ, 736, 19 Carr, M., Belton, M., Chapman, C., \& Davies, M. 1998, Natur, 391, 363 Cohen, R., Downs, G., Emerson, R., et al. 1987, MNRAS, 225, 491 Cordes, J. M., \& Lazio, T. J. 1991, ApJ, 376, 123

Cordes, J. M., \& Lazio, T. J. W. 2002, arXiv:astro-ph/0207156v3

Cordes, J. M., Lazio, T. J. W., \& Sagan, C. 1997, ApJ, 487, 782

Eatough, R. P., Keane, E. F., \& Lyne, A. G. 2009, arXiv:0901.3993v1

Gnedin, O. Y., Brown, W. R., \& Geller, M. J. 2010, ApJL, 720, L108

Gruenspecht, H. 2010, World Energy Outlook 2010 (Danvers, MA: OECD)

Hollis, J. M., Jewell, P. R., Lovas, F. J., \& Remijan, A. 2004, ApJL, 613, L45

Iglesias-Groth, S. 2011, MNRAS, 411, 1857

Kardashev, N. S. 1964, SvA, 8, 217

Kasting, J. F., Whitmire, D. P., \& Reynolds, R. T. 1993, Icar, 101, 108

Korpela, E., Werthimer, D., Anderson, D., Cobb, J., \& Lebofsky, M. 2001, CiSE, 3,78

Kuan, Y. J., Charnley, S. B., Huang, H. C., Tseng, W. L., \& Kisiel, Z. 2003, ApJ, 593,848

Leigh, D. 1998, PhD thesis, Harvard Univ.

Lovas, F. J., Hollis, J. M., Remijan, A. J., \& Jewell, P. R. 2006, ApJL, 645, L137

Marcy, G. W., \& Howard, A. W. 2011, in IAU Symp. 276, The Astrophysics of Planetary Systems: Formation ed. A. Sozzetti, M. G. Lattanzi, \& A. P. Boss (Cambridge: Cambridge Univ. Press), 3

Mehringer, D. M., Snyder, L. E., Miao, Y., \& Lovas, F. J. 1997, ApJL, 480, L71 Morabito, D. D. 2009, RaSc, 44, 6004

Morrison, P., Billingham, J., \& Wolfe, J. 1977, The Search for Extraterrestrial Intelligence (Moffett Field, CA: NASA)

Narayan, R. 1992, RSPTA, 341, 151

Perillat, P. 2012,

Rickett, B. J. 1990, ARA\&A, 28, 561

Robin, A. C., Reylé, C., Derrière, S., \& Picaud, S. 2003, A\&A, 409, 523

Schopf, J. W., Kudryavtsev, A. B., Agresti, D. G., Wdowiak, T. J., \& Czaja, A. D. 2002, Natur, 416, 73

Siemion, A. P. V., et al. 2011, arXiv:1109.1136

Siemion, A. P. V., Bower, G. C., Foster, G., et al. 2012, ApJ, 744, 109

Taylor, J. H. 1974, A\&AS, 15, 367

Woo, R. 1978, ApJ, 219, 727

Woo, R. 2007, SpWea, 5, 09004

Woo, R., \& Armstrong, J. W. 1979, JGR, 84, 7288 